ANA PAULA FIORETTI

\title{
EPIDEMIOLOGIA GENÉTICA DA INTRADERMORREAÇÃO DE MONTENEGRO EM UMA LOCALIDADE DE RONDÔNIA
}

\begin{abstract}
Dissertação apresentada ao Programa de Pós-graduação Biologia da Relação Patógeno-Hospedeiro do Instituto de Ciências Biomédicas da Universidade de São Paulo, para obtenção do Título de Mestre em Ciências Biológicas.
\end{abstract}


ANA PAULA FIORETTI

\section{EPIDEMIOLOGIA GENÉTICA DA INTRADERMORREAÇÃO DE MONTENEGRO EM UMA LOCALIDADE DE RONDÔNIA}

Dissertação apresentada ao Programa de Pós-graduação Biologia da Relação Patógeno-Hospedeiro do Instituto de Ciências Biomédicas da Universidade de São Paulo, para obtenção do Título de Mestre em Ciências Biológicas.

Área de Concentração: Parasitologia

Orientador: Prof. Dr. Henrique Krieger 
DADOS DE CATALOGAÇÃO NA PUBLICAÇÃO (CIP)

Serviço de Biblioteca e Informação Biomédica do

Instituto de Ciências Biomédicas da Universidade de São Paulo

(C) reprodução total

Fioretti, Ana Paula.

Epidemiologia genética da intradermorreação de Montenegro em uma localidade de Rondônia / Ana Paula Fioretti. -- São Paulo, 2009.

Orientador: Henrique Krieger.

Dissertação (Mestrado) - Universidade de São Paulo. Instituto de Ciências Biomédicas. Departamento de Parasitologia. Área de concentração: Biologia da Relação Patógeno-Hospedeiro. Linha de pesquisa: Epidemiologia genética.

Versão do título para o inglês: Genetic epidemiology of Montenegro skin test in a locality of Rondônia.

Descritores: 1. Epidemiologia genética 2. Bioestatística 3. Leishmania 4. Genética de populações 5. Rondônia I. Krieger, Henrique II. Universidade de São Paulo. Instituto de Ciências Biomédicas. Programa de Pós-Graduação em Biologia da Relação Patógeno-Hospedeiro III. Título. 
Candidato(a):

Título da Dissertação:

Orientador(a):
Ana Paula Fioretti.

Epidemiologia genética da intradermorreação de Montenegro em uma localidade de Rondônia.

A Comissão Julgadora dos trabalhos de Defesa da Dissertação de Mestrado, em sessão pública realizada a .I.................................,
( ) Aprovado(a)
( ) Reprovado(a)

Examinador(a): Assinatura:

Nome:

Instituição:

Examinador(a): Assinatura:

Nome:

Instituição:

Presidente:

Assinatura:

Nome:

Instituição: 
A todas as pessoas que fizeram parte da amostra coletada em Monte Negro, RO. 


\section{AGRADECIMENTOS}

Ao Departamento de Parasitologia e ao laboratório de Epidemiologia Genética pelo programa de pós-graduação: Biologia da Relação Patógeno-Hospedeiro do Instituto de Ciências Biomédicas da Universidade de São Paulo.

Ao Professor Doutor Henrique Krieger pela orientação, paciência, credibilidade e amizade.

A todos os meus colegas de laboratório, especialmente ao Ricardo, Carlos e Leandro por sempre estarem presentes, pelo apoio, paciência, dedicação e amizade.

À minha família pelo apoio.

Ao $\mathrm{CNPq}$, Conselho Nacional de Desenvolvimento Científico e Tecnológico e à FAPESP, Fundação de Amparo à pesquisa do Estado de São Paulo. 


\section{RESUMO}

FIORETTI, A. P. Epidemiologia genética da intradermorreação de Montenegro em uma localidade de Rondônia. 2009. 56 f. Dissertação (Mestrado em Parasitologia) - Instituto de Ciências Biomédicas, Universidade de São Paulo, São Paulo, 2009.

A distribuição familial da resposta ao extrato antigênico da Leishmania foi analisada sobre o prisma da epidemiologia genética. O exame utilizado para medir a resposta do organismo ao antígeno estudado foi a intradermorreação de Montenegro (IDRM). O presente trabalho utilizou uma amostra de 313 indivíduos do município de Monte Negro, RO. O objetivo foi detectar a evidência de um componente genético importante na determinação da expressão da característica em estudo. As análises estatísticas da amostra foram realizadas por meio do programa SPSS e as análises de segregação foram feitas utilizando o modelo unificado de análise de segregação (LALOUEL et al., 1983) do programa de computador POINTER. Com a finalidade de retirar efeitos concomitantes foram feitos cálculos de regressão múltipla escalonada e correlação entre os pares dentro das famílias. Os resultados da regressão múltipla escalonada indicaram que as variáveis idade e sexo estão correlacionadas com a resposta ao extrato antigênico da Leishmania. As correlações entre os pares dentro das famílias sugeriram a existência de agregação familial com forte componente genético, já que não foi encontrada correlação significante entre os pais. Esta agregação familial foi confirmada pela análise de segregação complexa que mostrou que o modelo mais adequado para explicar a transmissão do fenótipo na população de Monte Negro foi o monogênico recessivo.

Palavras-chave: Rondônia. Epidemiologia genética. Bioestatística. Leishmania. Genética de Populações. 


\begin{abstract}
FIORETTI, A. P. Genetic epidemiology of Montenegro skin test in a locality of Rondônia. 2009. 56 p. Master thesis (Parasitology) - Instituto de Ciências Biomédicas, Universidade de São Paulo, São Paulo, 2009.

The familial distribution of the response to an antigenic extract of Leishmania was analyzed by applying genetic epidemiology methods. Montenegro skin tests (MST) used to measure the human response to a Leishmania antigen. The present study tested a sample of 313 individuals from the Monte Negro, RO. The objective was to ascertain the relative importance of genetic components in the expression of the studied characteristic. Statistical analyses were performed using SPSS program and complex segregation analysis was made using the unified model of complex segregation analysis (LALOUEL et al., 1983). In order evaluate which effect acts on MST a stepwise multiple regression and correlation between the pairs in the families, was applied. The results of stepwise multiple regression showed that age and gender affect significantly MST. Correlations between of pairs within of families suggested the existence of a significant familial aggregation with a strong genetic component since no significant correlation was found among parents. This familial aggregation was confirmed by complex segregation analysis, which showed that the best model to explain the phenotype transmission in the Monte Negro population was the monogenic recessive one.
\end{abstract}

Key words: Rondônia. Genetic epidemiology. Bioestatistic. Leishmania. Population genetics. 


\section{LISTA DE ILUSTRAÇÕES}

Figura 1 -Localização do município de Monte Negro, RO........................................ 21

Figura 2 - Intradermorreação de Montenegro (IDRM).............................................. 23

Figura 3 - Distribuição dos indivíduos da amostra de Monte Negro de acordo com a

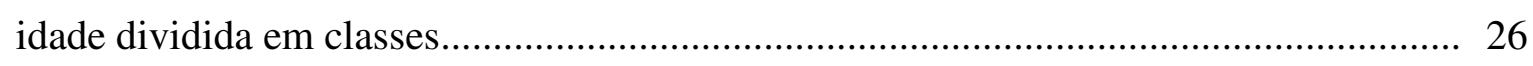

Figura 4 - Distribuição dos 313 indivíduos de acordo com idade e sexo........................ 27

Quadro 1 - Distribuição das respostas ao extrato antigênico da Leishmania por classe

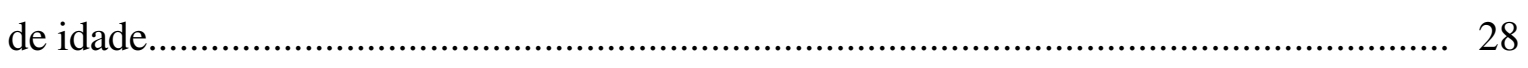

Quadro 2 - Distribuição do fenótipo estudado por classe de idade do sexo

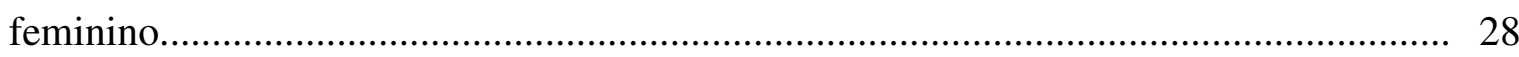

Quadro 3 - Distribuição do fenótipo estudado por classe de idade do sexo masculino

Quadro 4 - Distribuição da amostra de pais, mães e filhos de Monte Negro, segundo o

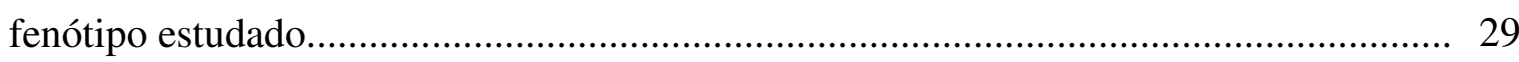

Figura 5 - Distribuição do fenótipo na amostra....................................................... 30

Figura 6 - Distribuição do $\log +1$ do fenótipo na amostra......................................... 31

Quadro 5 - Distribuição da variável "MN_3_classes"................................................. 32

Quadro 6 - Distribuição da variável "MN_qualit"....................................................... 32

Figura 7 - Distribuição do fenótipo "MN_padrão"

Figura 8 - Distribuição do fenótipo "MN_3_padrão".................................................. 37

Figura 9 - Distribuição do fenótipo "Qualit_padrão" .................................................. 38 


\section{LISTA DE TABELAS}

Tabela 1 - Modelos propostos para a variável "MNlogaritmo"

Tabela 2 - Coeficientes de regressão levando em conta a variável "MNlogaritmo".

Tabela 3 - Modelos propostos para a variável "MN_3_classes".

Tabela 4 - Coeficientes de regressão levando em conta a variável "MN_3_classes"..... 33

Tabela 5 - Modelos propostos para a variável "MN_qualit".

Tabela 6 - Coeficientes de regressão levando em conta a variável

"MN_qualit".

Tabela 7 - Resultados de testes de associação entre diferentes marcadores genéticos clássicos e a variável "MN_padrão".

Tabela 8 - Correlações da variável MN_padrão

Tabela 9 - Correlações da variável "MN_3_padrão".

Tabela 10 - Correlações da variável "Qualit_padrão".

Tabela 11 - Análise de segregação em "MN_padrão" levando em conta 102 famílias nucleares com 310 indivíduos

\section{TABELAS DOS ANEXOS}

Tabela A.1 - Análise de segregação em "MN_3_padrão", levando em conta 102 famílias nucleares com 310 indivíduos

Tabela A.2 - Análise de segregação em "Qualit_padrão", levando em conta 102 famílias nucleares com 310 indivíduos. 


\section{SUMÁRIO}

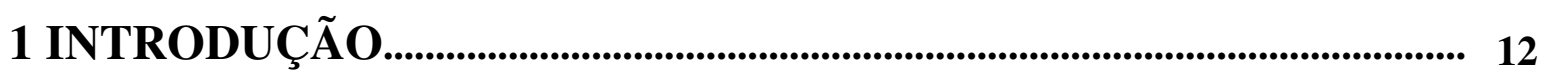

1.2 Epidemiologia Genética................................................................................... 13

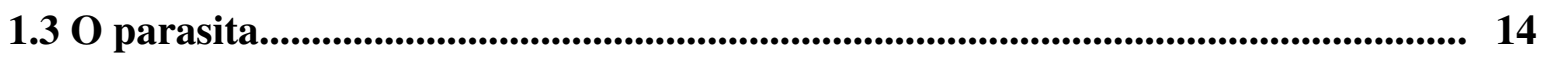

1.4 A resposta do organismo.................................................................................................. 15

1.5 A doença........................................................................................................................... 16

1.6 Intradermorreação de Montenegro (IDRM) …………................................................ 17

$1.7 \mathrm{O}$ fenótipo estudado............................................................................................................. 18

2 OBJETIVO....................................................................................................... 20

3 MATERIAIS MÉTODOS................................................................ 21

3.1 O município de Monte Negro, RO....................................................................... 21

3.2 A casuística................................................................................................................ 22

3.3 Teste de Montenegro (IDRM) ............................................................................... 23

3.4 Tratamento Estatístico................................................................................................. 24

4 RESULTADOS........................................................................................................ 26

4.1 Regressão Múltipla Escalonada............................................................................. 33

4.2 Padronização das Variáveis............................................................................................ 35

4.3 Correlação................................................................................................................... 40

4.3.1 Correlação Intraclasse............................................................................................. 40

4.4 Análise de segregação complexa....................................................................................... 43

5 DISCUSSÃO E CONCLUSÃO........................................................................... 46

REFERENCIAS.............................................................................................. 49

ANEXOS......................................................................................................................................... 55 


\section{INTRODUÇÃO}

A epidemiologia genética estuda a etiologia, distribuição e controle de doenças em grupos de indivíduos aparentados e procura conhecer as causas herdáveis das doenças nas populações (MORTON, 1982). O presente trabalho utiliza métodos da epidemiologia genética com a finalidade de investigar a existência de mecanismos genéticos no homem associados à resposta do organismo ao extrato antigênico de Leishmania.

Existem evidências de que a variação nos genes leva os indivíduos a desenvolverem diferentes respostas imunológicas a várias doenças parasitárias. De modo que a busca por esses genes pode produzir avanços na prevenção ou na cura de várias infecções (LIDOLPOVÁ e DEMANT, 2006).

A intersecção de estudos de mecanismos genéticos com a resposta do organismo às Leishmanias sp. permitiu comparar em estudos recentes, o efeito de genes na resposta imune (LIDOLPOVÁ e DEMANT, 2006). A resposta do organismo ao extrato antigênico da Leishmania nos indivíduos da amostra analisada pode estar fortemente associada às características genéticas além das características do ambiente. O entendimento dos fatores de riscos ambientais e genéticos que determinam porque pessoas com a mesma exposição a infecções diferem quanto à resposta de seus organismos podem aumentar o entendimento dos mecanismos da patogênese das leishmanioses que são críticos para o desenvolvimento da infecção (BLACKWELL et al., 2009).

O exame utilizado para medir a resposta do organismo ao antígeno estudado foi a intradermorreação de Montenegro (IDRM) produzido pela Fundação Osvaldo Cruz (FIOCRUZ), um diagnóstico imune celular complementar para leishmanioses cutâneas ou tegumentares. 


\subsection{Epidemiologia Genética}

O estudo genético epidemiológico está associado às características demográficas da população, como migração, fertilidade, mortalidade, distribuição etária, que podem ser vitais para o entendimento da distribuição de doenças em famílias e podem fornecer indícios importantes para o entendimento da resposta dos organismos às infecções (CAMARGO et al., 2002).

Apesar da maior parte das doenças infecciosas ocorrerem devido à exposição ambiental a microrganismos específicos, os genes também podem influenciar a resposta dos indivíduos às infecções (HILL, 2006).

A aceitação de um componente genético atuando em determinada resposta às doenças infecciosas depende de certas condições, como a ocorrência de indivíduos com resistência ao contágio, associação familial da moléstia infecciosa, variação racial da prevalência ou incidência da resposta e associação entre polimorfismos e moléstias infecciosas (BEIGUELMAN, 1994).

No Brasil existem diversas regiões com alta prevalência de doenças infecciosas, porém, existem poucos trabalhos relacionados à investigação da existência de componentes genéticos atuando nas respostas a essas infecções, a maioria deles foi feito em populações africanas ou em modelos animais. Estudos genéticos epidemiológicos em áreas endêmicas fornecem informações importantes como distribuição populacional e a variabilidade da gravidade da infecção (CARTER e MENDIS, 2002).

Estudos de epidemiologia genética realizados em diversas populações visando a resposta do organismo as leishmanioses indicaram a existência de agregação familial significante. Diferenças étnicas também estão envolvidas no avanço e na progressão da doença. Além disso, análises preliminares sugeriram a existência de fatores genéticos atuando na infecção, com a possível existência de um gene principal atuando na resistência ou suscetibilidade à leishmaniose tegumentar (KRIEGER e FEITOSA, 1999).

Em analogia a modelos murinos, foi possível constatar que a resposta do organismo às Leishmanias pode ser dependente de importantes mecanismos genéticos da espécie humana. Esses estudos, utilizando infecções experimentais de Leishmania donovani mostraram que as diversas linhagens isogênicas de camundongos reagiam de maneira distinta à infecção por esses microrganismos. O fato observado mais notável foi o de que essas diferenças entre linhagens não eram apenas dependentes de causa genética, mas de mecanismos mendelianos de herança (BLACKWELL, 1985). 
A procura de um mecanismo genético associado à variabilidade da resposta à IDRM pode aumentar o entendimento da patogênese das leishmanioses tegumentares, esclarecer as bases genéticas da resposta do organismo ao extrato antigênico da Leishmania nas populações humanas e consequentemente ajudar a encontrar novas terapias para a infecção, além de fornecer mais elementos para o entendimento da resposta imune como um todo.

\subsection{0 parasita}

As Leishmanias são protozoários, agentes etiológicos das leishmanioses, pertencentes à ordem Kinetoplastida (HONIGBERG, 1963; VICKERMAN, 1976 apud REY, 2001), família Trypanossomatidae (DOFLEIN, 1901; WOODCOCK, 1906 apud REY, 2001), gênero Leishmania (ROSS, 1903 apud REY, 2001) e divididas em dois subgêneros, Leishmania e Viannia (REY, 2001).

No mundo foram registradas até o momento, aproximadamente 20 espécies patogênicas de Leishmanias. No Brasil as espécies notificadas que causam leishmanioses tegumentares são: Leishmania viannia guyanensis, Leishmania (V.) braziliensis, Leishmania (V.) lainsoni, Leishmania (V.) naiffi, Leishmania (V.) shawi, Leishmania leishmania amazonensis, Leishmania. (V.) lindenberg e a espécie que causa leishmaniose visceral é a Leishmania (L.) chagasi (REY, 2001; SILVEIRA et al., 2002). No Estado de Rondônia as espécies de Leishmania notificadas até o momento são: Leishmania (V.) braziliensis, Leishmania (V.) lainsoni e Leishmania (L.) amazonensis (MINISTÉRIO DA SAÚDE, 2007).

O parasita possui duas formas principais: uma promastigota (flagelada) encontrada no tubo digestivo do inseto vetor (flebotomíneos) das leishmanioses e em alguns meios de cultura artificiais, e outra amastigota (aflagelada), encontrada nos tecidos dos hospedeiros vertebrados (OMS, 2006; LAINSON, SHAW, 1992).

Durante o ciclo de vida do parasita, a fêmea do flebotomíneo infectada extrai sangue do hospedeiro e introduz as formas promastigotas. O parasita cai na corrente sanguínea e é fagocitado pelos macrófagos, as formas promastigotas se transformam em amastigotas dentro dos macrófagos, ocorre a multiplicação por fissão binária das amastigotas que como conseqüência rompem os macrófagos, caem novamente na corrente sanguínea e invadem outras células. Durante o repasto sanguíneo, a fêmea do flebotomíneo ingere sangue infectado, as células parasitadas se rompem no trato alimentar do inseto, as amastigotas se diferenciam em promastigotas no intestino médio do flebótomo e estas se multiplicam 
(estádio próciclico), se tornam infecciosas (estádio metacíclico), completando o ciclo (GONTIJO e CARVALHO, 2003).

Os eventos que ocorrerão quando as promastigotas se transformarem em amastigotas no interior dos macrófagos, dependerão da resposta do organismo e da espécie do parasita. Quando acontece a recuperação espontânea da infecção ocorre o desenvolvimento da imunidade celular, quando não há uma resposta imune celular adequada, as Leishmanias atingem as células do sistema reticulo endotelial possibilitando a manifestação da doença. $\mathrm{O}$ período habitual de incubação é de 3 a 18 meses, podendo o parasita permanecer latente por um tempo superior até que aconteça um comprometimento da imunidade celular (SILVA e CAMARGO, 2004).

\subsection{A resposta do organismo}

As Leishmanias, após serem inoculadas na pele do hospedeiro humano podem sofrer a ação do sistema complemento, porém as formas infectantes resistem a essa ação. Essas formas promastigostas são suscetíveis à ação de células de Langerhans, neutrófilos e monócitos, mas ao penetrar no hospedeiro são fagocitadas pelos macrófagos, livrando-se do ataque dessas outras células do sistema imune. Os macrófagos são as células alvos principais das Leishmanias sp. e estão presentes em todos os tecidos corporais dos hospedeiros. (MACHADO et al., 2004).

Estudos feitos em camundongos infectados com Leishmania sp. trouxeram informações importantes quanto à resposta do hospedeiro ao parasita e indicaram que essa resposta pode ser determinada pela ativação de diferentes classes de células $\mathrm{T}$ helper (Th). Análises usando camundongos infectados por Leishmania major demonstraram que resposta do organismo hospedeiro quanto à resistência ao parasita parece estar associada a um perfil de citocinas T helper 1 (Th1) que produzem interferon $\gamma$ (IFN- $\gamma$ ), enquanto que a suscetibilidade parece estar correlacionada com células T helper 2 (Th2) que produzem interleucina 4 (IL-4) (REIS et al., 2006; LIPOLDOVÁ e DEMANT, 2006). Já as investigações em camundongos infectados por Leishmania amazonensis demonstraram altos níveis de produção de IL-4 e IL10 (associada à suscetibilidade) e baixos níveis de IFN- $\gamma$ (associada à resistência), além disso, estudos sugerem que a suscetibilidade de camundongos à L. amazonensis não é exclusivamente controlada por células Th2 e que existem outros mecanismos de indução de suscetibilidade ainda não claros (JI et al., 2002; AFONSO, SCOTT, 1993). 
Vários estudos indicaram que fatores imunológicos adicionais também estão associados à resposta do hospedeiro. A produção de interleucina 10 (IL-10) por células T parece sugerir uma explicação para a resposta do tipo "não cura" em algumas linhagens de camundongos que exibem uma resposta Th1. Outros componentes do sistema imune também exercem funções importantes, a interleucina 12 (IL-12) que é liberada pelos macrófagos e é um importante fator de estimulação da resposta Th1, células dendríticas e neutrófilos têm função regulatória, estimulando respostas Th1 ou Th2 nos indivíduos (LIPOLDOVÁ e DEMANT, 2006; REIS et al., 2006; BITTAR et al., 2007).

Em áreas endêmicas, entre os infectados, indivíduos assintomáticos são bastante freqüentes, sugerindo que muitas das populações expostas ao parasita adquirem a infecção sem desenvolver a doença e apresentam resposta positiva quanto à IDRM indicando o desenvolvimento de uma hipersensibilidade tardia para os antígenos da Leishmania (BITTAR et al., 2007).

\subsection{A doença}

As leishmanioses são consideradas pela Organização Mundial de Saúde como uma das cinco doenças parasitárias endêmicas de maior importância (OMS, 2006). Com uma prevalência mundial de 12 milhões de pessoas infectadas, as leishmanioses ameaçam 350 milhões de homens, mulheres e crianças no mundo (DESJEUX, 1992). Segundo estimativa da Organização Mundial da Saúde (OMS), as leishmanioses ocorrem em 88 países, dos quais 22 são do Novo Mundo.

No período de 1990 a 2006, a leishmaniose tegumentar vem apresentando taxa média de incidência de 16,72 a cada 100.000 habitantes, no Brasil. Em Rondônia, no mesmo período, foram registrados 30.096 novos casos da doença, com taxa de incidência de 133,39 a cada 100.000 habitantes (MINISTÉRIO DA SAÚDE, 2007).

A leishmaniose visceral, entre 1990 a 2006, apresentou taxa média de incidência de 1,65 a cada 100.000 habitantes no Brasil. Em Rondônia, no mesmo espaço de tempo, a taxa média de incidência a cada 100.000 habitantes foi de 0,01(MINISTÉRIO DA SAÚDE, 2007).

A manifestação das formas clínicas das leishmanioses depende da espécie de Leishmania, da resposta imune do indivíduo e da disseminação do parasita em determinados locais do corpo do indivíduo infectado (LAINSON e SHAW 1998). Quando as Leishmanias parasitam macrófagos da derme causam a forma cutânea da leishmaniose que pode ser localizada ou difusa, na mucosa elas causam leishmanioses mucocutânea e a disseminação do 
parasita para os macrófagos das vísceras causa a leishmaniose visceral (OMS, 2002; HERWALDT, 1999).

A forma cutânea (LC) no Brasil é causada principalmente pela Leishmania (V.) braziliensis, mas as outras seis espécies presentes no país também podem causar a infecção. A infecção se caracteriza por lesão cutânea ulcerosa na região da picada do inseto vetor. Também pode ocorrer a forma cutânea disseminada, apresentando lesões cutâneas numerosas espalhadas por diversas áreas do corpo (MINISTÉRIO DA SAÚDE, 2006).

A forma cutânea difusa (LCD) é uma forma rara e grave da LC, ocorre em pacientes com deficiência específica na resposta imune celular contra antígenos de Leishmania. (REY, 2001). O parasita responsável pela doença no Brasil pertence à espécie Leishmania (L.) amazonensis (COSTA, 1998). O início da manifestação clínica se dá por aparecimento de lesões cutâneas em formas de placas infiltradas, ou seja, não ulceradas que tendem a difundirse gradualmente (REY, 2001).

No Brasil a maioria dos casos de leishmaniose mucosa (LM) está associada à Leishmania (V.) braziliensis, excepcionalmente pode ser causada pela Leishmania (V.) guyanensis e Leishmania (L.) amazonensis. A LM se caracteriza por lesões mucosas principalmente em locais da face e excepcionalmente nos membros (GONTIJO e CARVALHO, 2003).

O agente etiológico da leishmaniose visceral no Brasil é a Leishmania (L.) chagasi. A infecção causa lesões superficiais que tendem a desaparecer, acomete o fígado, baço e medula óssea podendo causar óbito (RODAS e POLETTO, 2000).

\subsection{Intradermorreação de Montenegro (IDRM)}

A IDRM é um diagnóstico imunológico celular, realizado por intermédio da injeção intradérmica de uma suspensão de antígenos de promastigotas mortas de Leishmania (MONTENEGRO, 1926).

É uma reação de hipersensibilidade tardia, sua especificidade é de aproximadamente $100 \%$ e a sensibilidade varia segundo a literatura entre 84 e $100 \%$ para as formas cutâneas e mucocutâneas respectivamente (GUEDES, CUCÉ, FURTADO, 1990). Estas características, aliadas ao baixo custo, tornam este teste um dos principais exames complementares para o diagnóstico de leishmanioses cutâneas em áreas endêmicas (REY, 2001).

A IDRM constitui uma ferramenta importante também no diagnóstico retrospectivo da leishmaniose, portanto útil para inquéritos epidemiológicos. Uma reação de Montenegro 
positiva em indivíduos de áreas endêmicas sem história de leishmaniose tegumentar americana e sem qualquer lesão suspeita aponta para a possibilidade de formas abortivas ou infecções subclínicas (PASSOS, 2004).

Na forma cutânea, a resposta celular específica é bem modulada, com predominância de citocinas do tipo 1, portanto, nesta forma a imunidade celular está preservada sendo verificada na IDRM (NOGUEIRA, SOTTO, CUCÉ, 2008).

Na LCD, o teste cutâneo de Montenegro é geralmente negativo devido à ausência de resposta celular específica. A resposta predominante na LCD é a do tipo secretório (produção de anticorpos), em detrimento da resposta celular. O perfil 1 de citocinas da resposta imune nestes casos é predominantemente do tipo 2, com baixa produção de IFN- $\gamma$ e níveis altos de IL-10 (MEDDEB-GARNAOUI, ZRELLI, DELLAGI, 2008; PASSOS, 2004).

$\mathrm{Na}$ LM, a IDRM é fortemente positiva devido a resposta celular tipo 1 exacerbada e pela escassez de parasitas. A resposta proliferativa e a produção de IFN- $\gamma$ e de fator de necrose tumoral alfa (TNF- $\alpha$ ) estimuladas por antígenos de Leishmania em culturas de células mononucleares de sangue periférico também são significativamente maiores do que as observadas na LC. Isto é o que ocorre na chamada forma mucosa clássica. No entanto, é importante ressaltar que, em alguns casos o surgimento de lesões mucosas não se acompanha de exacerbação da resposta do tipo 1, como em pacientes imunocomprometidos (NOGUEIRA, SOTTO, CUCÉ, 2008).

Já a forma LV, geralmente, apresenta resposta negativa à IDRM durante a infecção e tende a se positivar após a cura da doença, isso porque durante a infecção há predominância de citocinas do tipo 2 com alto nível de anticorpos específicos, enquanto que após a cura o indivíduo infectado tende a desenvolver uma resposta celular do tipo 1 (STÄGER, SMITH e KAYE, 2000; MINISTÉRIO DA SAÚDE, 2007).

Vale ressaltar que no presente trabalho, o uso do teste de Montenegro não tem a intenção de diagnosticar casos de leishmaniose tegumentar e, sim verificar a existência de resposta ao antígeno utilizado.

\subsection{O fenótipo estudado}

A resposta do organismo ao extrato antigênico da Leishmania de agora em diante será chamada de fenótipo. A expressão do fenótipo estudado pode variar em função de vários fatores como: 
$>$ A estrutura da regulação imunológica do hospedeiro e suas características genéticas (CÁSTES et al., 1983).

> Características genéticas das Leishmanias sp. durante a relação parasita hospedeiro (CÁSTES et al., 1983).

$>$ Características do inseto vetor como alguns componentes de sua saliva que podem estar associados com a resposta do organismo ao antígeno (LAURENTI et al., 2009).

$>$ Fatores ambientais como temperatura, vegetação local, etc.

$>$ Reação cruzada com outras espécies de Leishmanias sp. diferentes da utilizada pela FIOCRUZ (CUBA-CUBA et al., 1985).

> Reação cruzada também em indivíduos com doença de Chagas e indivíduos curados de leishmaniose visceral (CUBA-CUBA et al., 1985).

> Resultados falsos negativos quando a leishmaniose tegumentar é precoce, ou em casos em que a doença cutânea seja causada por Leishmania amazonensis (SILVEIRA et al., 1991).

> Sensibilização do indivíduo quanto ao teste da IDRM, que poderá mostrar resultado positivo em um segundo teste (JOSE et al., 2001). 


\section{OBJETIVO}

Investigar, no espectro da variação do fenótipo estudado (IDRM), a possibilidade de detectar a evidência de um componente genético importante na determinação da expressão do fenótipo na amostra populacional estudada, além das variações dos fatores já conhecidos. 


\section{MATERIAIS E MÉTODOS}

O Departamento de Parasitologia do Instituto de Ciências Biomédicas (ICB) da Universidade de São Paulo está desenvolvendo um amplo programa de pesquisas na Amazônia ocidental brasileira. Nesse programa, o laboratório de Epidemiologia Genética desse Departamento participou do projeto temático denominado "Investigação científica da etiologia e clínica de algumas doenças tropicais na região de Monte Negro, Rondônia”, sob a responsabilidade dos Profs. Dr. Henrique Krieger e Dr. Luís Marcelo Aranha Camargo. O projeto foi aprovado pela comissão de ética através do parecer 322/CEP, emitido em 19/07/2002, cuja pesquisa desenvolveu-se dentro das normas éticas de acordo com a comissão e recebeu apoio financeiro da Fundação de Amparo à Pesquisa do Estado de São Paulo (FAPESP) e Conselho Nacional de Desenvolvimento Científico e Tecnológico (CNPq).

\subsection{O município de Monte Negro, RO}

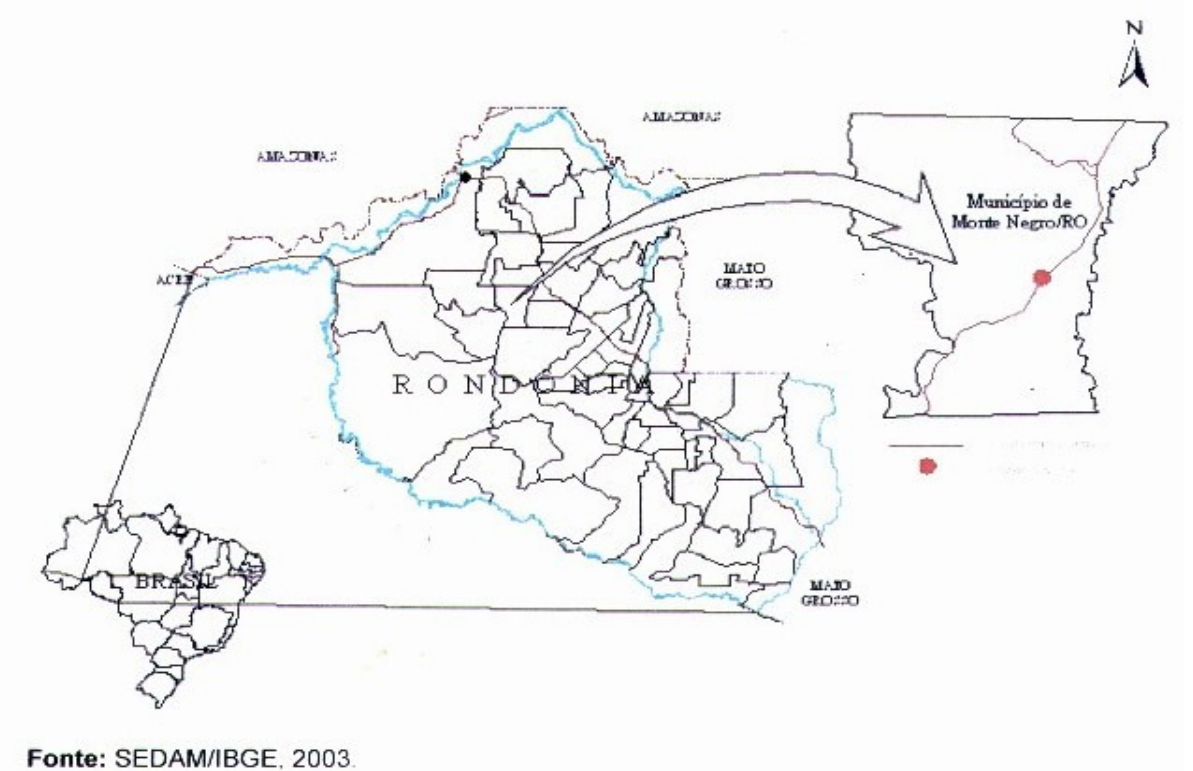

Figura 1 - Localização do município de Monte Negro, RO.

O município de Monte Negro (S 10² 15' 43.4”e W $63^{\circ} 17^{\prime}$ 49.2”) possui aproximadamente 13.000 habitantes e é atualmente formado por migrantes originários do sul e sudeste do Brasil, principalmente Paraná e Minas Gerais, parte dos quais está se miscigenando seja com os descendentes dos habitantes que vieram principalmente do nordeste 
brasileiro, durante o período áureo da exploração da borracha (1880 até 1910), seja com aqueles que descendem dos primeiros habitantes locais e que apresentam acentuado componente ameríndio. A principal ocupação da maioria dos homens adultos da população de Monte Negro (96\%) está relacionada à agricultura, enquanto que cerca de $80 \%$ das mulheres adultas se dedicam às atividades domésticas. O analfabetismo atinge cerca de $20 \%$ dos adultos, entre as crianças essa porcentagem diminui para 6\%. As famílias vivem em casas de madeira e um terço delas tem acesso à energia elétrica. Nas famílias, a idade média dos pais e das mães é 41,9 anos $\pm 13,21$ e 36,3 anos $\pm 13,35$, respectivamente. Na geração filial a idade média em anos dos meninos e das meninas é, respectivamente, 12,2 anos $\pm 8,77$ e 10,46 anos \pm 7,37 (CAMARGO et al., 2002).

A população de Monte Negro está exposta a um ambiente fortemente seletivo, que torna difícil a sobrevivência de indivíduos de idade mais avançada, e, ao mesmo tempo, mostra alta taxa de fecundidade, o que provoca um aumento dos grupos etários mais jovens (CAMARGO et al., 2002).

O Estado de Rondônia abriga um ecossistema constantemente ameaçado pela ação transformadora do homem, resultando em um desequilíbrio que pode facilitar a aproximação do vetor ao homem e hipoteticamente facilitar a transmissão de vários patógenos, entre estes a leishmaniose tegumentar (MASSARO, REZENDE, CAMARGO, 2008).

A composição étnica da população de Monte Negro é formada por Africanos 0,25 \pm 0,032, Ameríndios 0,12 \pm 0,046 e Caucasóides 0,63 \pm 0,054. Foi estimada empregando o método de verossimilhança máxima de Krieger et al. (1965) e usando o programa Mistura (CABELLO e KRIEGER, 1997).

\subsection{A casuística}

Foi extraída uma amostra aleatória, no município de Monte Negro, de 924 indivíduos, os quais foram examinados clinicamente e tratados, quando necessário, por uma equipe que inclui ao menos um médico, enfermeiras, assistentes sanitárias e assistentes sociais. Deve-se evidenciar que todos os adultos dessa população que contribuíram para as pesquisas realizadas deram seu consentimento para participarem do estudo. No caso dos menores de idade o mesmo tipo de consentimento foi obtido de seus pais ou responsáveis.

Dos 924 indivíduos da amostra, 313 foram submetidos à intradermorreação de Montenegro, onde o tamanho da resposta variou de 0 a 20 milímetros (mm). Também foi colhida uma amostra de sangue, que serviu, em parte, para a determinação dos grupos 
sanguíneos dos sistemas ABO (antígenos A, B), MNS (antígenos M, N, S, s), Rh (antígenos C, c, D, E, e), Kell (K, k) e Duffy (Fy ${ }^{\mathrm{a}}$ e Fy ${ }^{\mathrm{b}}$ ), as haptoglobinas (Hp) e hemoglobinas (Hb) e as enzimas eritrocitárias Desidrogenase de 6-fosfato de Glicose (G-6-PD), glioxalase (GLO), fosfoglucomutase (PGM) e esterase D (Esd).

\subsection{Teste de Montenegro (IDRM)}

A prova foi efetuada utilizando o Kit Montenegro para Leishmania, do Instituto de Tecnologia em Imunobiológicos Bio-Manguinhos da FIOCRUZ (FIOCRUZ, 2008).

Desde 1992, o Bio-Manguinhos, cuja função é a produção de vacinas e insumos para diagnósticos, vem produzindo antígeno para reação de Montenegro a partir do cultivo de Leishmania amazonensis, fornecida pelo Centro de Referência Internacional de Caracterização de Cepas de Leishmania, do Departamento de Imunologia da FIOCRUZ (PASSOS, 2004).

A cepa de Leishmania amazonensis é isolada a partir de flebotomíneos da região amazônica. A escolha desse parasita deve-se a sua facilidade de crescimento em meio de cultivo in vitro, boa antigenicidade e utilização por diferentes laboratórios (PASSOS, 2004).

$\mathrm{O}$ antígeno foi diluído em uma suspensão salina fenolada a $0,4 \%$. Injetou-se $0,1 \mathrm{ml}$ na face interna do antebraço de cada indivíduo da amostra. Após 48 a 72 horas, fez-se a leitura onde o aparecimento de uma pápula eritematosa, com base dura, com diâmetro $\geq 5 \mathrm{~mm}$ foi considerado positivo para a IDRM (REY, 2001; FIOCRUZ, 2008).
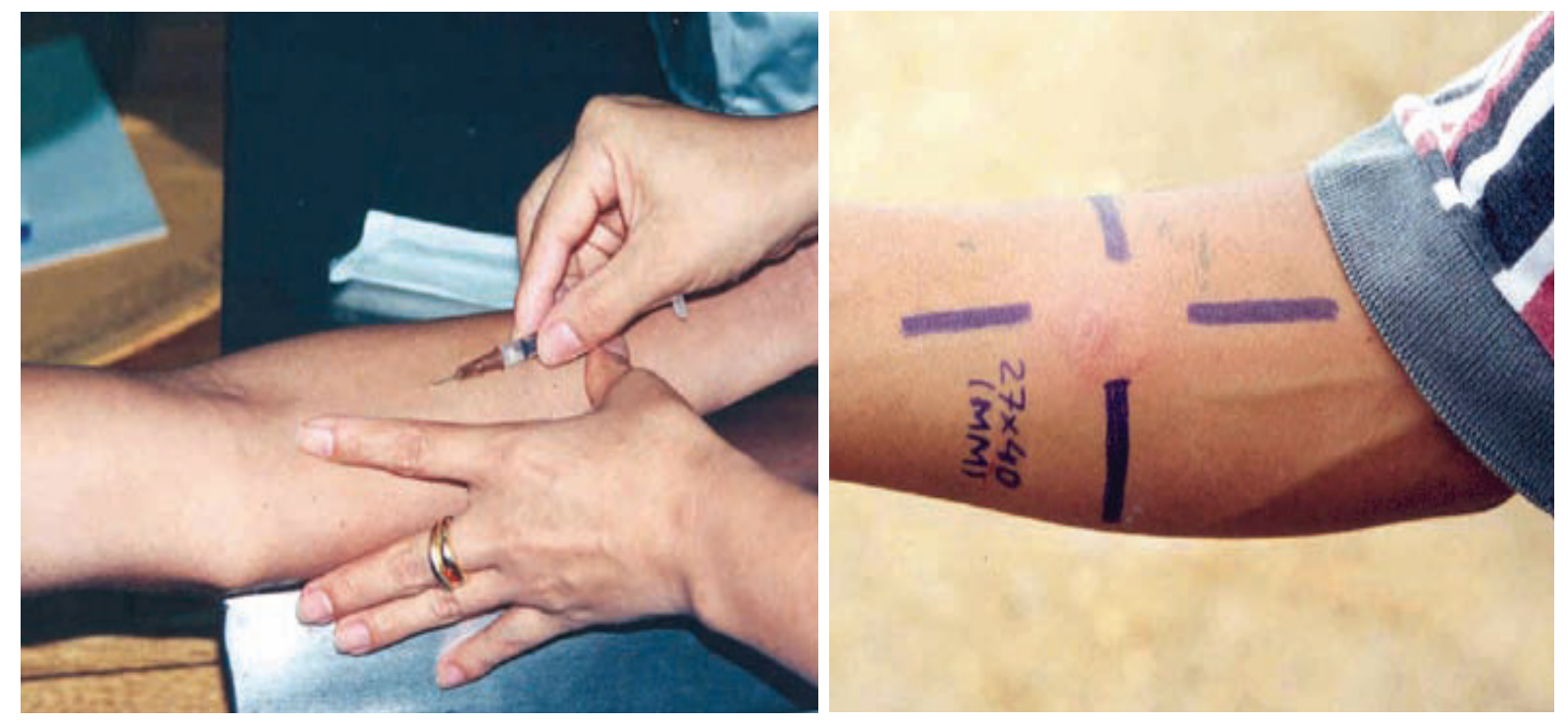

Figura - 2 Intradermorreação de Montenegro (IDRM).

Fonte: Ministério da Saúde, 2006. 


\subsection{Tratamento Estatístico}

As análises estatísticas da amostra como regressão e correlação foram realizadas por meio do programa SPSS. Nos resultados de regressão múltipla escalonada foram aplicados a correção de Bonferroni que é um método que ajusta o nível de significância quando se testa hipóteses com duas ou mais variáveis independentes sobre uma variável dependente (ABDI, 2007).

A análise de segregação é uma das ferramentas da epidemiologia genética que estuda dados familiares com a finalidade de estabelecer o modo de herança de uma determinada característica, essa análise foi feita usando o modelo unificado de análise de segregação do programa de computador POINTER (LALOUEL et al., 1983). Para testar a hipótese de existência de um mecanismo genético atuando na manifestação do fenótipo é necessário averiguar a distribuição nas famílias do fenótipo em estudo, nesse caso, a amostra foi dividida em 102 famílias nucleares completas ou incompletas.

As variáveis utilizadas foram:

“Montenegro_MN", onde o tamanho da resposta em mm variou de 0 a 20;

$>$ posição na família, onde, 1 = pai, 2 = mãe e 3 = filhos;

$>$ idade (em anos);

$>$ sexo, onde, $1=$ masculino e $0=$ feminino.

As variáveis calculadas posteriormente foram:

$>(\text { Idade })^{2}$;

$>$ Sexo x idade;

$>\operatorname{Sexo} \times(\text { idade })^{2}$;

> "MNlogaritmo" (logaritmo da IDRM + 1), "MNcorrigida" e "MN_padrão";

> “MN_3_classes", resultados da IDRM divididos em 3 classes: $0 \mathrm{~mm}=0,1$ a 4 $\mathrm{mm}=1$ e 5 a $20 \mathrm{~mm}=2$; "MN3_corrigida" e "MN_3_padrão";

$>$ "MN_qualit", resultados da IDRM divididos qualitativamente: 0 a $4 \mathrm{~mm}=0$ (negativo) e 5 a $20 \mathrm{~mm}=1$ (positivo); "MN_qualit_corrigida" e “Qualit_padrão”.

O termo "corrigida" nas variáveis calculadas "MNcorrigida", "MN3_corrigida" e "MN_qualit_corrigida" indica que as variáveis foram corrigidas para as variáveis 
independentes sexo, idade e seus produtos. O termo "padrão" nas variáveis calculadas "MN_padrão", "MN_3_padrão" e "Qualit_padrão" indica que as variáveis foram padronizadas $(\mathrm{Y}-\mathrm{Yo}) / \mathrm{DP}$. 


\section{RESULTADOS}

Os 313 indivíduos da amostra foram distribuídos em cinco classes etárias.

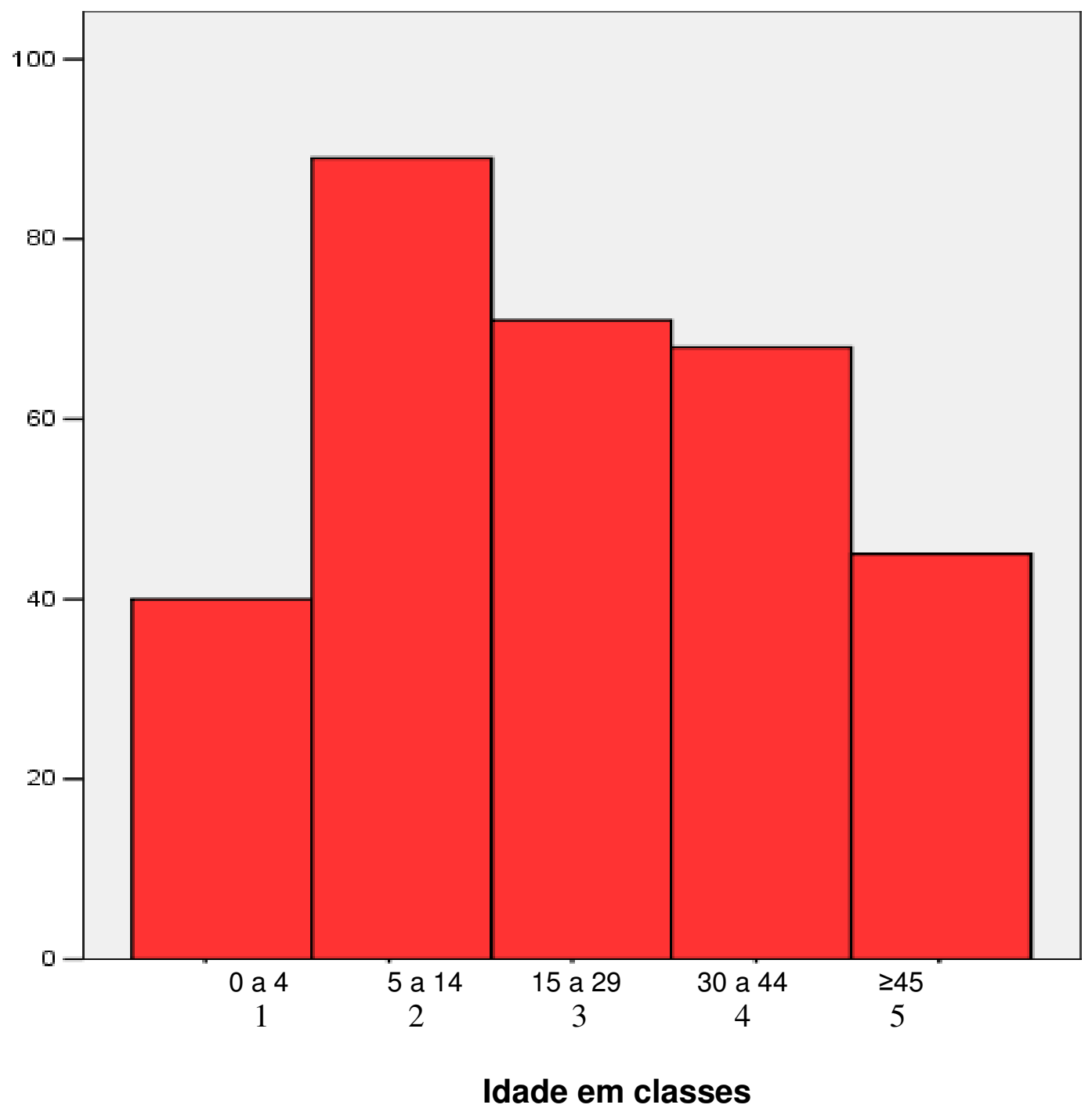

Figura 3 - Distribuição dos indivíduos da amostra de Monte Negro de acordo com a idade dividida em classes.

A figura 3 mostra que a maior parte da população pertence à classe 2 (faixa etária de 5 a 14 anos, com 89 indivíduos). 


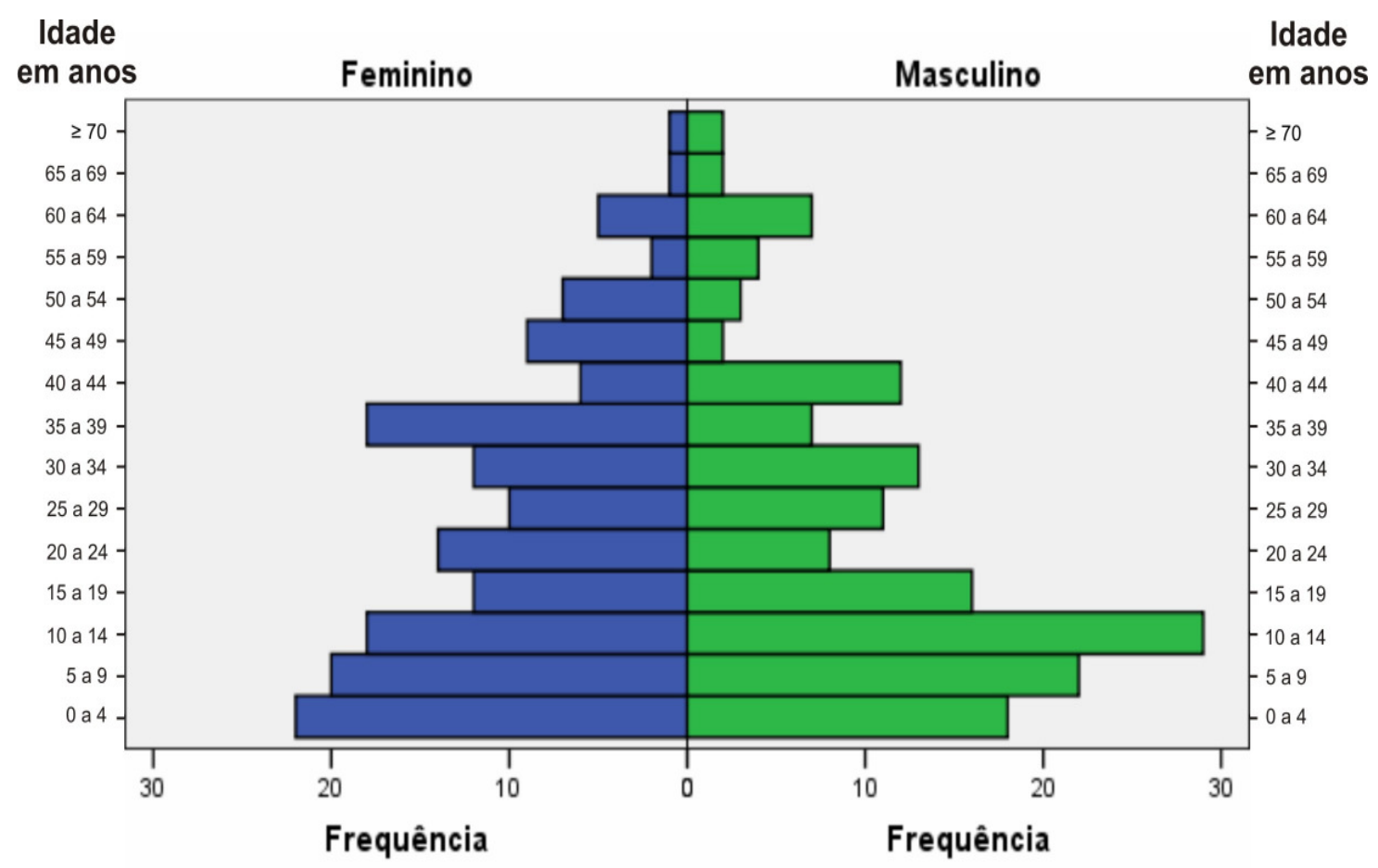

Figura 4 - Distribuição dos 313 indivíduos de acordo com idade e sexo.

A figura 4 mostra a distribuição dos indivíduos de acordo com a idade e o sexo, sendo que a maior parte dos indivíduos do sexo masculino se concentra na faixa etária de 10 a 14 anos, enquanto que a maioria dos indivíduos do sexo feminino possui idade entre 0 e 4 anos.

É uma pirâmide populacional típica de populações subdesenvolvidas com um número bem maior de indivíduos jovens do que aqueles com idade mais avançada.

A razão entre os sexos dos indivíduos da amostra é de 1,01, pois a amostra possui 157 mulheres e 156 de homens. 
A distribuição da resposta à IDRM por idade (Quadro 1), por sexo (Quadros 2 e 3) e por estrutura familial (Quadro 4) na amostra, foi obtida por intermédio do teste de Kruskal Wallis.

O quadro 1 mostra que a classe de idade de 15 a 29 anos tem maior incidência de respostas ao extrato antigênico da Leishmania, com posto médio de 184,35. Os indivíduos com $\geq 45$ anos de idade tiveram o valor de 183,22 no posto médio. A classe de idade com menor incidência de respostas são os indivíduos de 0 a 4 anos com posto médio de 107,21. De forma geral, pode ser observado um aumento de incidência de respostas conforme aumenta a idade.

Quadro 1 - Distribuição das respostas ao extrato antigênico da Leishmania por classe de idade.

\begin{tabular}{|ccc|}
\hline Idade dividida em classes & N & $\begin{array}{c}\text { Posto médio } \\
\text { da IDRM }\end{array}$ \\
\hline 0 a 4 & 40 & 107,21 \\
5 a 14 & 89 & 132,14 \\
15 a 29 & 71 & 184,35 \\
30 a 44 & 68 & 172,92 \\
$\geq 45$ & 45 & 183,22 \\
Total & 313 & \\
\hline
\end{tabular}

Quadro 2 - Distribuição do fenótipo estudado por classe de idade do sexo feminino.

\begin{tabular}{|ccc|}
\hline Idade dividida em classes (feminino) & N & $\begin{array}{c}\text { Posto médio } \\
\text { da IDRM }\end{array}$ \\
\hline 0 a 4 & 22 & 62,60 \\
5 a 14 & 38 & 66,13 \\
15 a 29 & 36 & 93,53 \\
30 a 44 & 36 & 84,19 \\
$\geq 45$ & 25 & 84,60 \\
Total & 157 & \\
\hline
\end{tabular}

$\mathrm{H}=14,014 \mathrm{P}=0,007$ 
Quadro 3 - Distribuição do fenótipo estudado por classe de idade do sexo masculino.

\begin{tabular}{|ccc|}
\hline Idade dividida em classes (masculino) & N & $\begin{array}{c}\text { Posto médio } \\
\text { da IDRM }\end{array}$ \\
\hline 0 a 4 & 18 & 45,33 \\
5 a 14 & 51 & 63,90 \\
15 a 29 & 35 & 92,26 \\
30 a 44 & 32 & 90,98 \\
$\geq 45$ & 20 & 101,55 \\
Total & 156 & \\
\hline $\mathrm{H}=30,62 \mathrm{P}=0,001$ & &
\end{tabular}

A partir da observação do quadro 2 infere-se que a idade que demonstra maior número de reações ao extrato antigênico da Leishmania no sexo feminino está na faixa de 15 a 29 anos, com posto médio de 93,53, e a idade que demonstra menor número de reações são os indivíduos de 0 a 4 anos com posto médio de 62,60. Já no quadro 3, a idade do sexo masculino que demonstra maior quantidade de reações é $\geq 45$ anos, com posto médio de 101,55 e a menor está entre a faixa etária de 0 a 4 anos com posto médio de 45,33 anos.

Quadro 4 - Distribuição de pais, mães e filhos de Monte Negro, segundo o fenótipo estudado.

\begin{tabular}{|ccc|}
\hline $\begin{array}{c}\text { Estrutura } \\
\text { familial }\end{array}$ & N & $\begin{array}{c}\text { Posto médio } \\
\text { da IDRM }\end{array}$ \\
\hline Pais & 56 & 193,86 \\
Mães & 81 & 146,15 \\
Filhos & 173 & 147,46 \\
Total & 310 & \\
$\mathrm{H}=42,76 \mathrm{P}=0,001$
\end{tabular}

O quadro 4 expõe o fenótipo estudado de pais e filhos, na qual se pode constatar que os indivíduos que mais demonstraram respostas ao extrato antigênico da Leishmania foram os pais, com posto médio de 193,86, em segundo lugar vem os filhos com posto médio de 147,46 . 


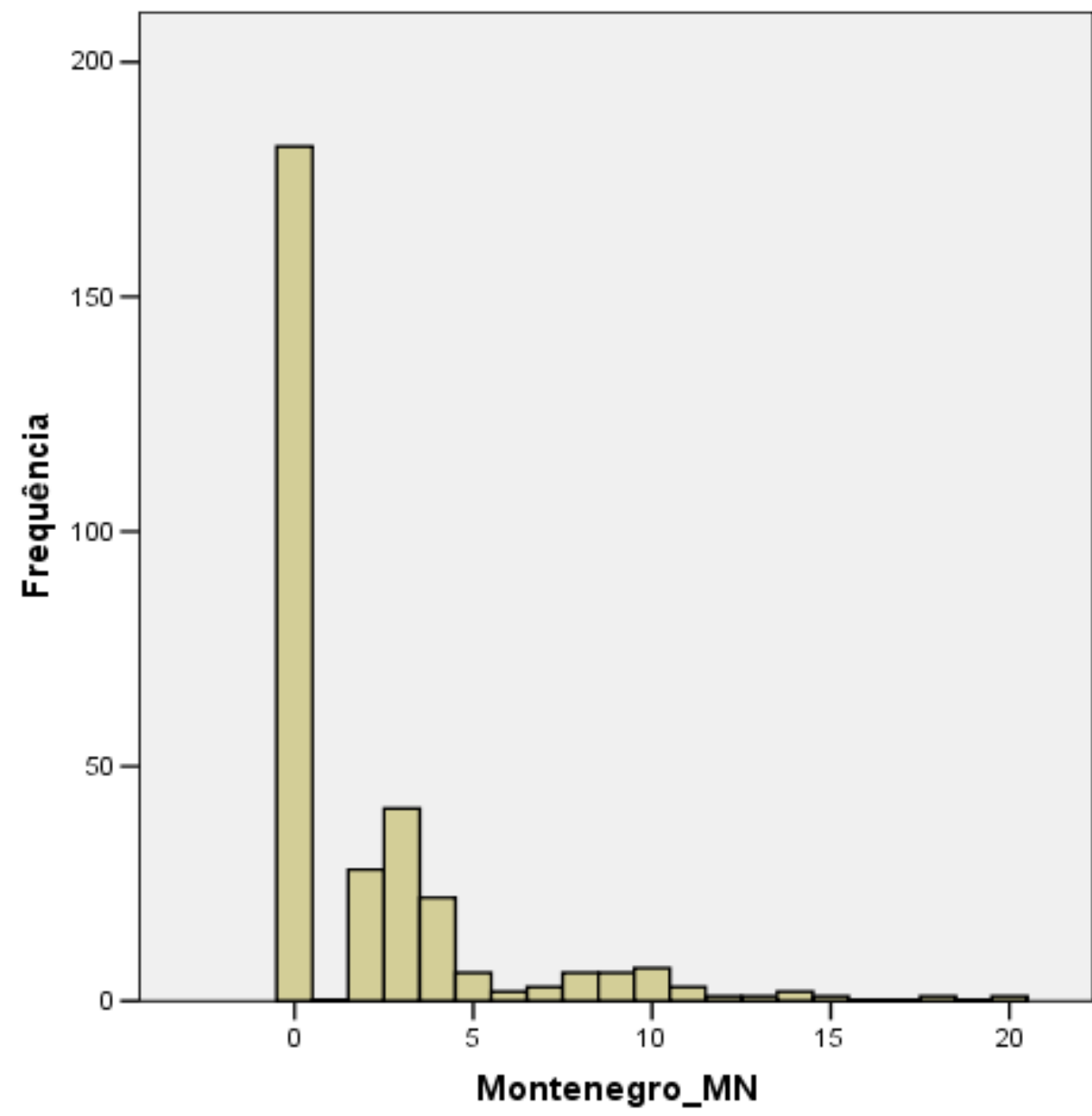

Mean $=2,05$

Std. Dev. $=3,338$

$N=313$

Figura 5 - Distribuição do fenótipo na amostra.

A figura 5 mostra a distribuição da variável "Montenegro_MN" que é o fenótipo em estudo, com a resposta variando de 0 a $20 \mathrm{~mm}$. O histograma apresenta uma curva binomial negativa com o valor da variância 11,14 bem maior do que a média com valor 2,05. 


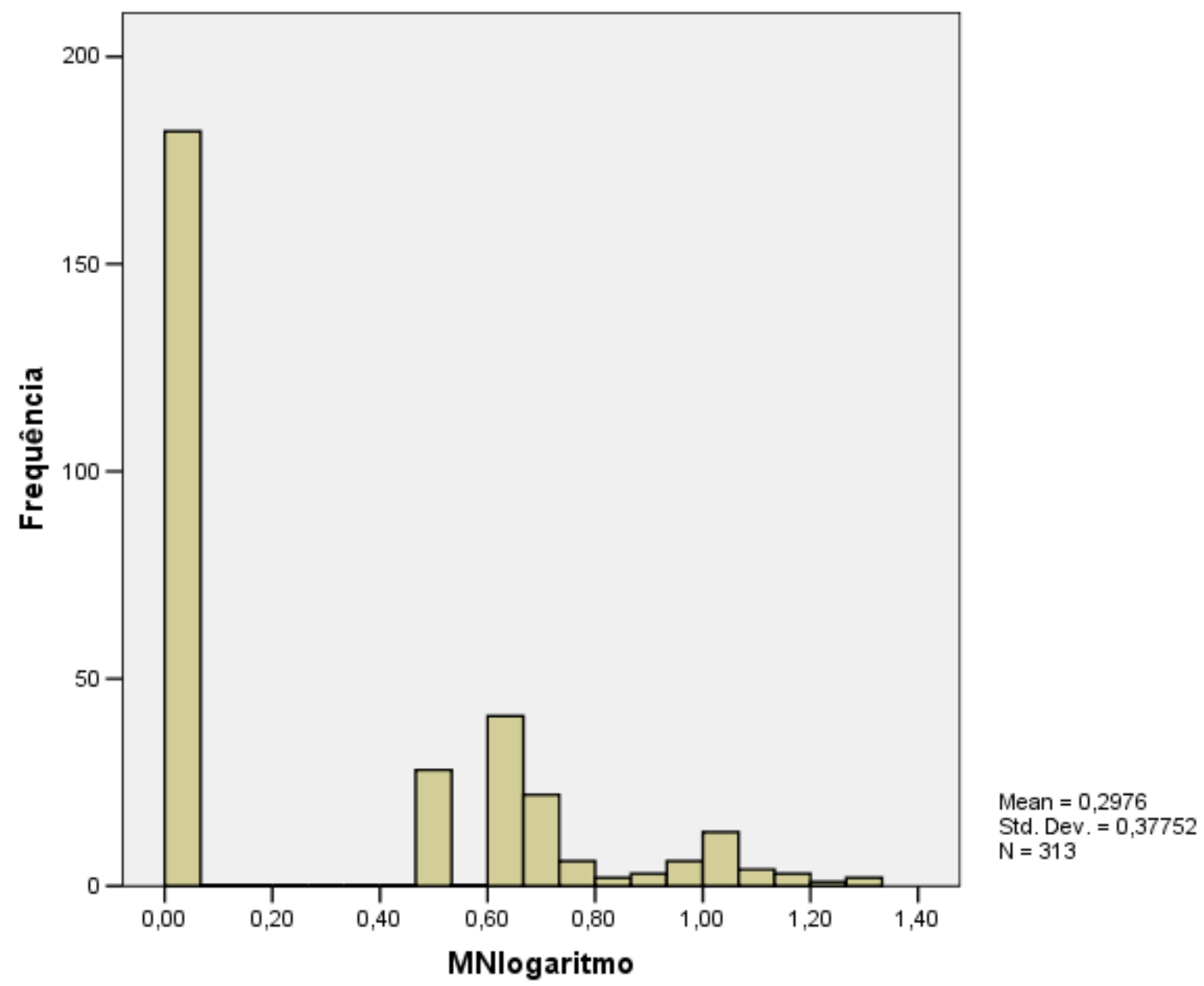

Figura 6 - Distribuição do $\log +1$ do fenótipo na amostra.

Devido à alta variância apresentada nos valores da variável "Montenegro_MN" na amostra estudada foi feita uma transformação logarítmica +1 com o objetivo de reduzir a amplitude da variância e foi criada a variável "MNlogaritmo" (Figura 6). 
Quadro 5 - Distribuição da variável "MN_3_classes".

\begin{tabular}{|cc|}
\hline IDRM & Frequência \\
\hline $0 \mathrm{~mm}$ & 182 \\
$1 \mathrm{a} 4 \mathrm{~mm}$ & 91 \\
5 a $20 \mathrm{~mm}$ & 40 \\
Total & 313 \\
\hline
\end{tabular}

O quadro 5 mostra a distribuição do fenótipo na amostra dividida em 3 classes. $\mathrm{O}$ valor da média da distribuição da variável "MN_3_classes" é 0,55 e o desvio padrão 0,71.

Quadro 6 - Distribuição da variável "MN_qualit".

\begin{tabular}{|cc|}
\hline IDRM & Frequência \\
\hline Negativo & 273 \\
Positivo & 40 \\
Total & 313 \\
\hline
\end{tabular}

O quadro 6 mostra a distribuição do fenótipo na amostra dividida em 2 classes (resposta negativa ou positiva). O valor da média da distribuição da variável "MN_qualit" é 0,13 e o desvio padrão é 0,33 . 


\subsection{Regressão Múltipla Escalonada}

Utilizando o conjunto de programas SPSS, regrediu-se as variáveis dependentes "MNlogaritmo", "MN_3_classes" e "MN_qualit" sobre as seguintes variáveis independentes sexo, idade, $(\text { idade })^{2}$, idade $\times$ sexo, $(\text { idade })^{2} \times$ sexo, a fim de verificar a existência de efeitos das mesmas. O modelo mais adequado foi o 3 (tabelas 1, 3 e 5) por apresentar o coeficiente de determinação mais alto $\left(\mathrm{R}^{2}\right.$ Ajustado $=0,187$ para "MNlogaritmo", $\mathrm{R}^{2}$ Ajustado $=0,182$ para “MN_3_classes" e R ${ }^{2}$ Ajustado = 0,192 para "MN_qualit"). As tabelas 2, 4 e 6 mostram os valores do modelo mais adequado para as variáveis dependentes.

Tabela 1 - Modelos propostos para a variável "MNlogaritmo".

\begin{tabular}{cccc}
\hline Modelo & $\mathbf{R}$ & $\mathbf{R}^{\mathbf{2}}$ Ajustado & Erro Padrão \\
\hline $\mathbf{1}$ & 0,355 & 0,123 & 0,353 \\
$\mathbf{2}$ & 0,377 & 0,183 & 0,351 \\
$\mathbf{3}$ & 0,437 & 0,187 & 0,341 \\
\hline
\end{tabular}

Tabela 2 - Coeficientes de regressão levando em conta a variável "MNlogaritmo".

\begin{tabular}{ccccc}
\hline Modelo & Variáveis & Coeficiente & Erro padrão & $\mathbf{P}$ \\
\hline $\mathbf{3}$ & Intercepto & $0,017(\mathrm{a})$ & 0,045 & $>0,010$ \\
& Idade $\times$ sexo $\left(\mathrm{x}_{1}\right)$ & $0,007(\mathrm{~b})$ & 0,001 & $<0,001$ \\
& Idade $\left(\mathrm{x}_{2}\right)$ & $0,018(\mathrm{c})$ & 0,004 & $<0,001$ \\
& (Idade) $^{2}\left(\mathrm{x}_{3}\right)$ & $-0,001(\mathrm{~d})$ & 0,000 & $<0,001$ \\
\hline
\end{tabular}

Nível de significância 0,01 de acordo com a correção de Bonferroni.

Tabela 3 - Modelos propostos para a variável "MN_3_classes".

\begin{tabular}{cccc}
\hline Modelo & $\mathbf{R}$ & $\mathbf{R}^{\mathbf{2}}$ Ajustado & Erro Padrão \\
\hline $\mathbf{1}$ & 0,357 & 0,125 & 0,665 \\
$\mathbf{2}$ & 0,379 & 0,138 & 0,660 \\
$\mathbf{3}$ & 0,435 & 0,182 & 0,643 \\
\hline
\end{tabular}

Tabela 4 - Coeficientes de regressão levando em conta a variável "MN_3_classes".

\begin{tabular}{ccccc}
\hline Modelo & Variáveis & Coeficiente & Erro padrão & P \\
\hline 3 & Intercepto & $0,024(\mathrm{a})$ & 0,085 & $>0,010$ \\
& Idade $\times$ sexo $\left(\mathrm{x}_{1}\right)$ & $0,013(\mathrm{~b})$ & 0,002 & $<0,001$ \\
& Idade $\left(\mathrm{x}_{2}\right)$ & $0,033(\mathrm{c})$ & 0,007 & $<0,001$ \\
& (Idade) $^{2}\left(\mathrm{x}_{3}\right)$ & $-0,001(\mathrm{~d})$ & 0,000 & $<0,001$ \\
\hline
\end{tabular}

Nível de significância 0,01 de acordo com a correção de Bonferroni. 
Tabela 5 - Modelos propostos para a variável "MN_qualit".

\begin{tabular}{cccc}
\hline Modelo & $\mathbf{R}$ & $\mathbf{R}^{\mathbf{2}}$ Ajustado & Erro Padrão \\
\hline $\mathbf{1}$ & 0,384 & 0,145 & 0,309 \\
$\mathbf{2}$ & 0,410 & 0,163 & 0,306 \\
$\mathbf{3}$ & 0,447 & 0,192 & 0,301 \\
\hline
\end{tabular}

Tabela 6 - Coeficientes de regressão levando em conta a variável "MN_qualit".

\begin{tabular}{ccccc}
\hline Modelo & Variáveis & Coeficiente & Erro padrão & P \\
\hline 3 & Intercepto & $0,051(\mathrm{a})$ & 0,024 & $>0,010$ \\
& Idade $\times$ sexo $\left(\mathrm{x}_{1}\right)$ & $0,027(\mathrm{~b})$ & 0,005 & $<0,001$ \\
& $(\text { Idade })^{2} \times \operatorname{sexo}\left(\mathrm{x}_{2}\right)$ & $-0,003(\mathrm{c})$ & 0,000 & $<0,001$ \\
& Sexo $\left(\mathrm{x}_{3}\right)$ & $-0,214$ (d) & 0,061 & $=0,001$ \\
\hline
\end{tabular}

Nível de significância 0,01 de acordo com a correção de Bonferroni.

O modelo escolhido por regressão conteve as variáveis idade, idade $^{2}$ e idade $\times$ sexo, nas variáveis "MNlogaritmo" e "MN_3_classes", tabelas 2 e 4 respectivamente, as variáveis sexo e (idade $)^{2} \times$ sexo foram excluídas uma vez que não foi encontrado efeito significante entre estas variáveis independentes e a IDRM.

Já o modelo escolhido por regressão na variável "MN_qualit", tabela 6, conteve as variáveis sexo, idade $\times$ sexo e $(\text { idade })^{2} \times$ sexo.

A análise da regressão fornece a variável corrigida pela seguinte equação:

$$
Y=\text { variável dependente }-\left(a+b x_{1}+c_{2}+d x_{3}\right)
$$

Onde temos:

$>$ Variável dependente = "MNlogaritmo" ou "MN_3_classes" ou "MN_qualit";

$>\mathrm{a}=$ intercepto, ou seja, expressa o valor de y quando $\mathrm{x}=0$;

b, c e d = coeficientes de regressão;

$>\mathrm{x}=$ variáveis independentes.

Após as regressões múltiplas escalonadas, as variáveis "MNlogaritmo", "MN_3_classes" e "MN_qualit" foram denominadas "MNcorrigida", "MN3_corrigida" e "MNqualit_corrigida" respectivamente, que são as variáveis corrigidas para idade e sexo. 


\subsection{Padronização das variáveis}

As variáveis "MNcorrigida", "MN3_corrigida" e "MN_qualit_corrigida" foram padronizadas com o intuito de evitar efeitos escalares e para posterior utilização nas estimativas de correlação. Foram criadas as variáveis "MN_padrão", "MN_3_padrão" e "Qualit_padrão" que representam os valores corrigidos com média $=0$ e desvio padrão $=1$ para os três tipos de variáveis.

A padronização das variáveis foi obtida pela seguinte equação:

\section{Variável padronizada $=(\mathrm{Y}-\mathrm{Yo}) / \mathrm{DP}$}

Onde temos:

$>$ Variável padronizada em termos de desvio da média, tendo como unidade o desvio padrão = "MN_padrão" ou "MN_3_padrão" ou “Qualit_padrão";

$>\mathrm{Y}=$ valor da variável corrigida para regressão;

$>$ Yo = variável observada;

$>\mathrm{DP}=$ desvio padrão da variável Y.

Portanto as três variáveis iniciais foram tratadas estatisticamente e passaram pelas seguintes transformações:

A variável inicial "MontenegroMN" (sem divisões, resposta 0 a $20 \mathrm{~mm}$ ) passou por uma transformação logarítmica + 1 e criou-se a variável "MNlogaritmo", que foi corrigida para idade e sexo originando a variável "MNcorrigida" e finalmente está foi padronizada se chamando então "MN_padrão".

A variável "MN_3_classes" (dividida em três classes), foi corrigida para idade e sexo originando a variável "MN3_corrigida" e finalmente esta foi padronizada se chamando então “MN_3_padrão".

A variável "MNqualit" (dividida qualitativamente), foi corrigida para idade e sexo originando a variável "MN_qualit_corrigida" e finalmente a mesma foi padronizada se chamando então "Qualit_padrão". 


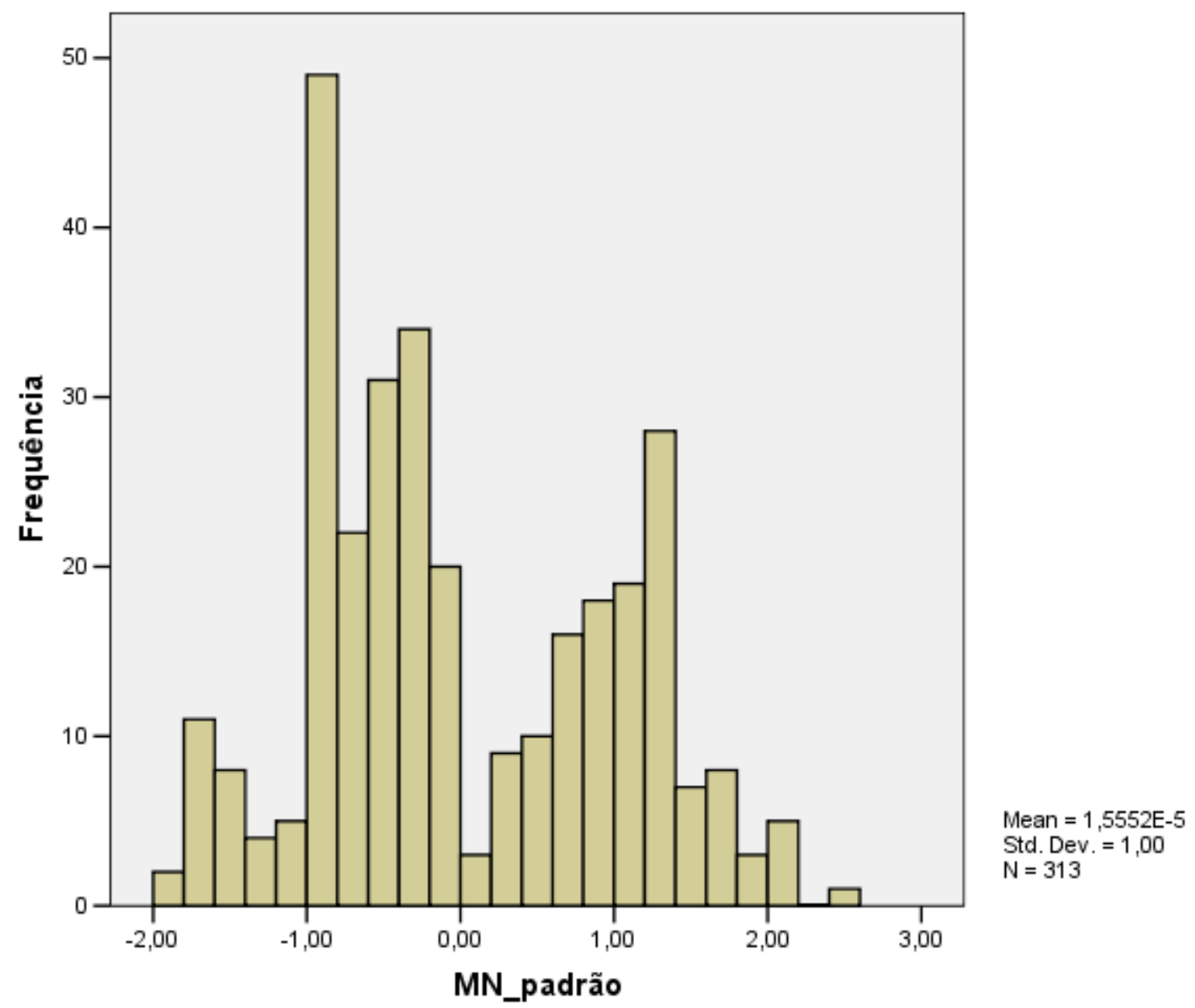

Figura 7 - Distribuição do fenótipo "MN_padrão".

A figura 7 mostra a distribuição da variável "MN_padrão", com média 0 e desvio padrão 1, distribuição aparentemente bimodal sugerindo população heterogênea. 


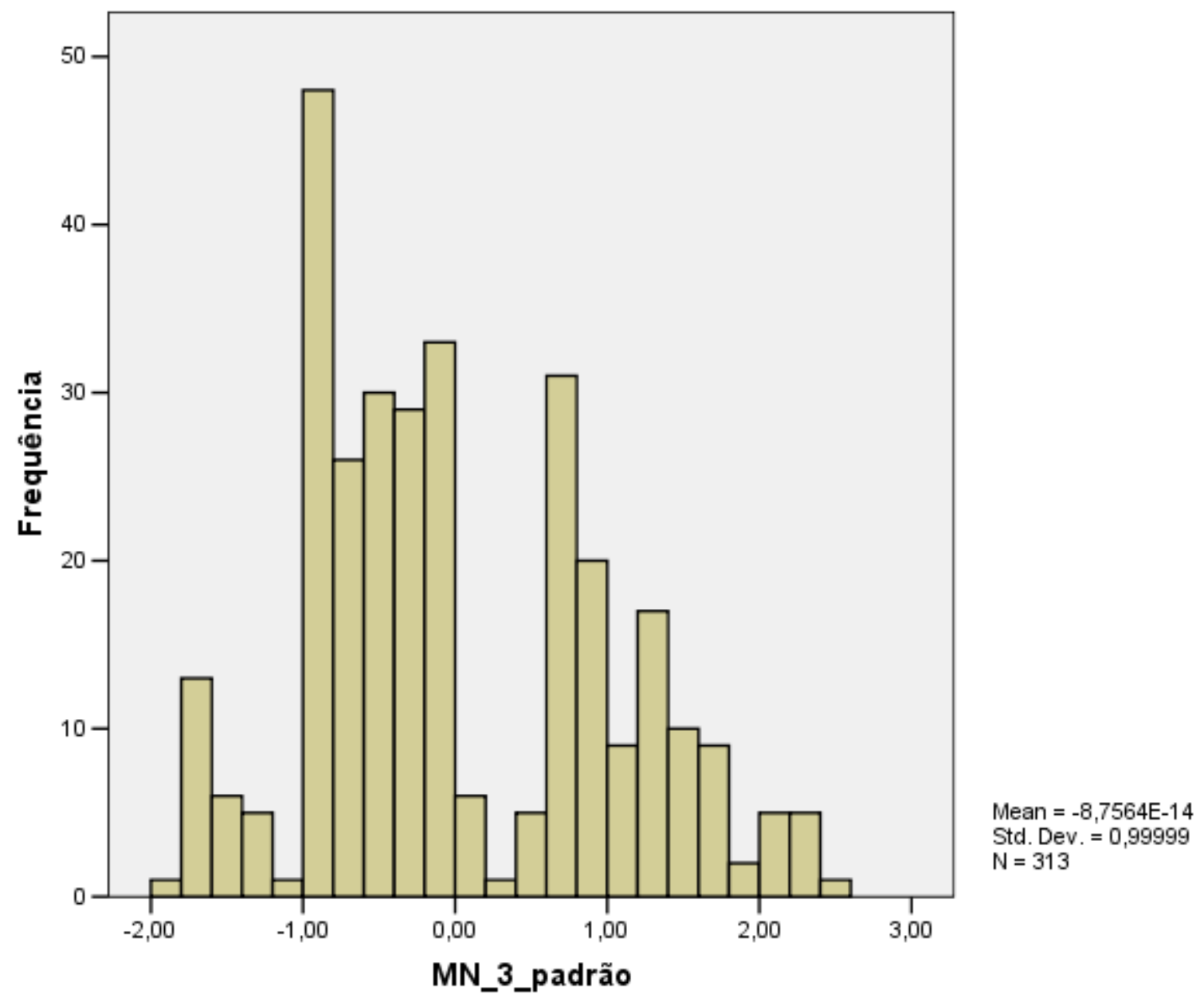

Figura 8 - Distribuição do fenótipo "MN_3_padrão".

A figura 8 mostra a distribuição da variável "MN_3_padrão", com média 0 e desvio padrão 1 . 


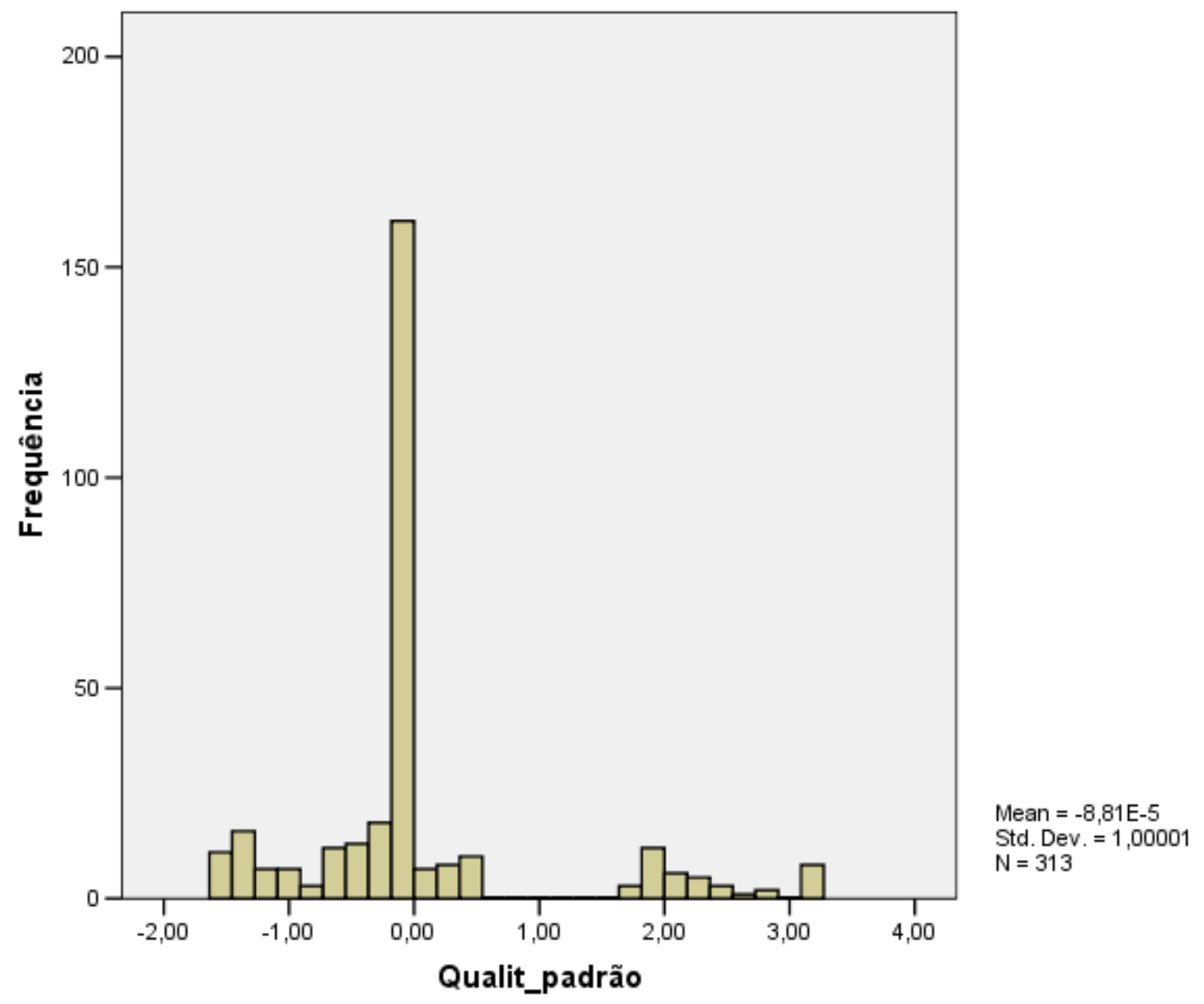

Figura 9 - Distribuição do fenótipo "Qualit_padrão”.

A figura 9 mostra a distribuição da variável "Qualit_padrão" com média 0 e desvio padrão 1 . 
Foram feitos testes de Kruskal-Wallis entre marcadores genéticos clássicos e o fenótipo "MN_padrão" com o objetivo de verificar a associação entre os genótipos analisados e a resposta ao extrato antigênico da Leishmania na população. Não foi necessário realizar o teste com as variáveis "MN_3_padrão" e "Qualit_padrão", uma vez que a variável "MN_padrão" foi suficiente para responder a hipótese de associações entre a IDRM e marcadores genéticos clássicos.

Tabela 7 - Resultados de testes de associação entre diferentes marcadores genéticos clássicos e a variável "MN_padrão".

\begin{tabular}{lccc}
\hline \multicolumn{1}{c}{ Fenótipos } & G. L. & $\boldsymbol{\chi}^{2}$ & P \\
\hline ABO & 3 & 3,155 & 0,368 \\
A+B+AB & 1 & 0,751 & 0,386 \\
B+AB & 1 & 1,150 & 0,284 \\
MNSus & 9 & 8,423 & 0,492 \\
MM MN NN & 2 & 2,812 & 0,245 \\
SS Ss Ss SuSu & 3 & 3,844 & 0,279 \\
Rh & 8 & 9,788 & 0,280 \\
CC Cc cc & 2 & 1,000 & 0,606 \\
D_dd & 1 & 0,004 & 0,951 \\
EE Ee ee & 2 & 0,260 & 0,878 \\
E_ee & 1 & 0,254 & 0,614 \\
Kell & 1 & 1,762 & 0,184 \\
Duffy & 3 & 2,357 & 0,502 \\
Fy(a-b-) & 1 & 0,684 & 0,408 \\
Hp & 3 & 3,749 & 0,290 \\
Hp1-1 & 1 & 1,619 & 0,203 \\
Hb & 3 & 3,076 & 0,380 \\
G-6-PD masculino & 1 & 0,155 & 0,693 \\
G-6-PD feminino & 2 & 1,809 & 0,405 \\
GLO & 2 & 3,617 & 0,164 \\
PGM 1 & 2 & 0,402 & 0,818 \\
EsD & 2 & 0,408 & 0,816 \\
\hline
\end{tabular}

G.L. = graus de liberdade, $\chi^{2}=$ qui-quadrado, $\mathrm{P}=$ probabilidade.

Os resultados dos $\chi^{2}$ e $\mathrm{P}$ mostrados na tabela 7 permitiram rejeitar a hipótese de associação entre qualquer marcador clássico e a resposta ao extrato antigênico da Leishmania. 


\subsection{Correlação}

Com a utilização de programas auxiliares desenvolvidos no laboratório, as variáveis "MN_padrão", "MN_3_padrão" e "Qualit_padrão" foram dispostas em pares de acordo com as famílias e separadas de acordo com a correlação a ser feita: "Média pais $\times$ cada filho", "Média pais $\times$ média filho", "Mãe $\times$ cada filho", "Pai $\times$ cada filho", "Pai $\times$ mãe", "Pai $\times$ média dos filhos", "Mãe $\times$ média dos filhos", "filhos intraclasse", em seguida os cálculos de correlação foram realizados pelo programa SPSS.

Os resultados da tabela 6, 7 e 8 mostram os coeficientes da correlação de Pearson. Foram realizados testes de correlação não paramétricas também (não apresentados), já que as variáveis padronizadas não tiveram distribuição normal, mas devido ao fato dos resultados serem semelhantes foram mantidos os resultados da correlação de Pearson, exceto a correlação entre irmãos que foi a intraclasse.

\subsubsection{Correlação Intraclasse}

A correlação intraclasse não pode ser feita por pares ordenados como as outras correlações, pois as variáveis foram corrigidas quanto à idade e principalmente porque existe um número variável de irmãos dentro de cada grupo. Sendo assim, foi utilizado o método de Lynch e Walsh (1998), onde a correlação intraclasse é igual à divisão de $\operatorname{Var}_{\text {(s) }}$ por Var (z):

$$
\begin{gathered}
\mathrm{r}_{\mathrm{i}}=\operatorname{Var}_{(\mathrm{s})} / \operatorname{Var}_{(\mathrm{z})} \\
\operatorname{Var}_{(\mathrm{s})}=\left(\mathrm{MSe}-\mathrm{MSd} / \mathrm{n}_{0}\right. \\
\operatorname{Var}_{(\mathrm{z})}=\operatorname{Var}_{(\mathrm{s})}+\operatorname{Var}_{(\mathrm{z})}, \text { onde } \\
\operatorname{Var}_{(\mathrm{e})}=\operatorname{MSd}
\end{gathered}
$$

$\mathrm{r}_{\mathrm{i}}=$ correlação intraclasse;

MSe $=$ média dos quadrados dos irmãos entre as famílias;

MSd = média dos quadrados dos irmãos dentro das famílias;

$\mathrm{n}_{0}=$ número médio de filhos por família. 
Tabela 8 - Correlações da variável "MN_padrão".

\begin{tabular}{|c|c|c|c|}
\hline Correlações dos pares & $\mathbf{N}$ & $\mathbf{r}$ & $\mathbf{P}$ \\
\hline Média pais $\times$ cada filho & 154 & 0,130 & 0,107 \\
\hline Média pais $\times$ média filhos & 66 & 0,140 & 0,264 \\
\hline Mãe $\times$ cada filho & 143 & 0,188 & $<0,05$ \\
\hline Pai $\times$ cada filho & 100 & $-0,013$ & 0,899 \\
\hline Pai $\times$ mãe & 47 & 0,109 & 0,465 \\
\hline Pai $\times$ média dos filhos & 40 & $-0,083$ & 0,610 \\
\hline Mãe $\times$ média dos filhos & 61 & 0,236 & 0,068 \\
\hline Entre irmãos & 173 & $-0,017$ & 0,900 \\
\hline
\end{tabular}

De acordo com a tabela 8, as correlações da variável "MN_padrão" demonstraram resultado positivo e estatisticamente significativo para o par "Mãe $\times$ cada filho", as correlações "Média pais $\times$ cada filho", "Média pais $\times$ média filhos", "Pai $\times$ mãe", "Mãe $\times$ média dos filhos", foram positivas mas não significantes e as correlações "Pai $\times$ cada filho", "Pai × média dos filhos" e "Entre irmãos" foram negativas.

Tabela 9 - Correlações da variável "MN_3_padrão".

\begin{tabular}{cccc}
\hline Correlações dos pares & $\mathbf{N}$ & $\mathbf{r}$ & $\mathbf{P}$ \\
\hline Média pais $\times$ cada filho & $\mathbf{1 5 4}$ & $\mathbf{0 , 1 8 2}$ & $<\mathbf{0 , 0 5}$ \\
Média pais × média filhos & 66 & 0,208 & 0,094 \\
Mãe $\times$ cada filho & $\mathbf{1 4 3}$ & $\mathbf{0 , 2 2 7}$ & $<\mathbf{0 , 0 1}$ \\
Pai × cada filho & 100 & 0,005 & 0,963 \\
Pai × mãe & 47 & 0,103 & 0,491 \\
Pai × média dos filhos & 40 & $-0,032$ & 0,845 \\
Mãe $\times$ média dos filhos & $\mathbf{6 1}$ & $\mathbf{0 , 2 7 2}$ & $<\mathbf{0 , 0 5}$ \\
Entre irmãos & 173 & 0,017 & 0,896 \\
\hline
\end{tabular}

$\mathrm{N}=$ tamanho amostral

$\mathrm{r}=$ coeficiente de correlação

Conforme pode ser observado na tabela 9, as correlações da variável "MN_3_padrão" mostram resultados positivos e significativos estatisticamente para "Média pais $\times$ cada filho", "Mãe $\times$ cada filho" e "Mãe $\times$ média dos filhos". O par "Pai $\times$ média dos filhos" mostrou 
correlação negativa e as demais foram positivas, mas não foi encontrada significância estatística.

Tabela 10 - Correlações da variável "Qualit_padrão".

\begin{tabular}{cccc}
\hline Correlações dos pares & $\mathbf{N}$ & $\mathbf{r}$ & $\mathbf{P}$ \\
\hline média pais $\times$ cada filho & $\mathbf{1 5 4}$ & $\mathbf{0 , 2 2 4}$ & $<\mathbf{0 , 0 1}$ \\
média pais $\times$ média filhos & $\mathbf{6 6}$ & $\mathbf{0 , 3 3 4}$ & $<\mathbf{0 , 0 1}$ \\
mãe $\times$ cada filho & $\mathbf{1 4 3}$ & $\mathbf{0 , 1 8 4}$ & $<\mathbf{0 , 0 5}$ \\
pai $\times$ cada filho & 100 & 0,144 & 0,153 \\
pai $\times$ mãe & 47 & 0,201 & 0,175 \\
Pai × média dos filhos & 40 & 0,242 & 0,132 \\
mãe $\times$ média dos filhos & $\mathbf{6 1}$ & $\mathbf{0 , 2 8 2}$ & $<\mathbf{0 , 0 5}$ \\
Entre irmãos & 173 & $-0,010$ & 0,903 \\
\hline
\end{tabular}

$\mathrm{N}=$ tamanho amostral

$\mathrm{r}=$ coeficiente de correlação

Já a tabela 10 mostra as correlações da variável "Qualit_padrão" que foram significantes entre "Média pais $\times$ cada filho", "Média pais $\times$ média filhos", "Mãe $\times$ cada filho" e "Mãe $\times$ média dos filhos", as demais foram positivas mas não significativas e a correlação "Entre irmãos” foi negativa. 


\subsection{Análise de segregação complexa}

Os cálculos da análise de segregação complexa (Tabela 11) foram feitos com a finalidade de investigar a existência de um mecanismo herdável responsável pela característica em estudo por meio do programa de computador POINTER (LALOUEL et al., 1983; LALOUEL e MORTON, 1981).

Os parâmetros desse programa são a média $(\mu)$, a variância $(\sigma)$, o grau de dominância $(d)$, o deslocamento $(t)$, a freqüência do alelo $(q)$, a herdabilidade $(H)$ e as taxas de transmissão entre duas gerações $(\tau)$ (FEITOSA e KRIEGER, 2002).

Esse método parte de um modelo mendeliano misto, o qual supõe que a manifestação da característica em estudo (fenótipo), depende da contribuição independente dos alelos de um loco autossômico principal, de um componente poligênico/multifatorial e de um resíduo ambiental não transmissível. Ainda nesse modelo mendeliano misto, no loco autossômico principal supõe-se a existência de um par de alelos $(A a)$ com freqüências $p$ e $q$, respectivamente, sendo $p$ e $q=1-\mathrm{p}$, e com a distribuição populacional dos genótipos resultantes $(A A, A a$ e $a a)$, conforme a lei de Hardy e Weinberg, ou seja, $\mathrm{p}^{2}+2 \mathrm{pq}+\mathrm{q}^{2}$ (BEIGUELMAN, 2005; FEITOSA e KRIEGER, 2002).

O modelo aleatório não estima nenhum dos parâmetros, ou seja, não considera a existência de mecanismos de transmissão $(q=H=0)$. Já no modelo que admite a inexistência de um gene principal, o único parâmetro a ser estimado é a $H$. No modelo sem componente multifatorial são estimados três parâmetros que são $d, t$ e $q$.

A transmissão recessiva foi estimada de duas maneiras, um modelo com $d$ fixado em 0 e o outro com $d$ e $H$ fixados em 0 . No modelo aditivo $d$ é fixado em 0,5 , enquanto que no modelo dominante $d$ é fixado em 1 .

Além disso, no modelo com $\tau$ s livres apenas $d$ é fixado em 1 , os valores de $\tau_{1}, \tau_{2}$ e $\tau_{3}$ são deixados livres para serem estimados pelo programa, com o objetivo de se testar os mecanismos de transmissão mendeliana.

Não foram encontrados valores para o modelo com $\tau$ iguais $\left(\tau_{1}=\tau_{2}=\tau_{3}\right)$ que consideraria a ausência de transmissão mendeliana no fenótipo em questão.

Os testes das hipóteses foram realizados por intermédio do quociente de verossimilhança que é igual a menos 2 vezes o logaritmo natural da verossimilhança máxima, ou seja, -2 ln L. A comparação entre os modelos é feita por meio da subtração de seus coeficientes $(-2 \ln \mathrm{L})$, que resulta em um qui-quadrado $\left(\chi^{2}\right)$, que juntamente com o coeficiente de Akaike (AIC) (AKAIKE, 1974), indica o modelo mais adequado. 
Os arquivos auxiliares, necessários para a utilização do programa POINTER foram preparados pelo programa NUCFAM. Foi criado um arquivo (*.dat) com os dados da população e um arquivo job file (*.jf) com as seguintes variáveis: número da família, grau de parentesco da família ou posição do indivíduo na família, sexo dos indivíduos e as variáveis "MN_padrão", "MN_3_classes" e "Qualit_padrão". A partir daí foram criados outros arquivos job file (*.jf) com os parâmetros dos modelos a serem estimados pelo programa POINTER. 


\subsubsection{Análise De Segregação Complexa}

Tabela 11 - Análise de segregação em “MN_padrão” levando em conta 102 famílias nucleares com 310 indivíduos.

\begin{tabular}{|c|c|c|c|c|c|c|c|c|c|c|c|c|c|}
\hline Modelo & $d$ & $t$ & $q$ & $\boldsymbol{H}$ & $\tau_{1}$ & $\tau_{2}$ & $\tau_{3}$ & $-2 \ln L$ & $\chi^{2}$ & $P$ & Teste & $P E$ & $A I C$ \\
\hline 1. Misto & $-0,007$ & 1,857 & 0,548 & 0,010 & {$[1]$} & {$[0,5]$} & {$[0]$} & 427,798 & & & & 4 & 435,798 \\
\hline 2. Aleatório & {$[0]$} & {$[0]$} & {$[0]$} & {$[0]$} & - & - & - & 451,690 & 23,892 & $<0,001$ & 2 vs. 1 & 0 & 451,690 \\
\hline 3. Sem gene principal & {$[0]$} & {$[0]$} & {$[0]$} & 0,097 & {$[1]$} & {$[0,5]$} & {$[0]$} & 450,963 & 23,165 & $<0,001$ & 3 vs. 1 & 1 & 452,963 \\
\hline 4. Sem componente multifatorial & $-0,004$ & 1,855 & 0,550 & {$[0]$} & {$[1]$} & {$[0,5]$} & {$[0]$} & 427,853 & 0,055 & $>0,900$ & 4 vs. 1 & 3 & 433,853 \\
\hline 5. Recessivo $(d=0)$ & {$[0]$} & 1,865 & 0,548 & 0,009 & {$[1]$} & {$[0,5]$} & {$[0]$} & 427,803 & 0,005 & $>0,999$ & 5 vs. 1 & 3 & 433,803 \\
\hline 5'. Recessivo $(d=0, H=0)$ & {$[0]$} & 1,860 & 0,551 & {$[0]$} & {$[1]$} & {$[0,5]$} & {$[0]$} & 427,848 & 0,050 & 0,970 & 5 ' vs. 1 & 2 & 431,848 \\
\hline 6. $\operatorname{Aditivo}(d=0,5)$ & {$[0,5]$} & 3,640 & 0,133 & 0,024 & {$[1]$} & {$[0,5]$} & {$[0]$} & 457,847 & 30,049 & $<0,001$ & 6 vs. 1 & 3 & 463,847 \\
\hline 7. Dominante $(d=1)$ & {$[1,0]$} & 1,560 & 0,011 & 0,080 & {$[1]$} & {$[0,5]$} & {$[0]$} & 450,857 & 23,059 & $<0,001$ & 7 vs. 1 & 3 & 456,857 \\
\hline 8. $\tau$ s livres $(d=1)$ & {$[1,0]$} & 6,346 & 0,925 & 0,062 & 1,000 & 0,000 & 0,000 & 445,878 & 18,030 & $<0,001$ & 8 vs. $5^{\prime}$ & 6 & 457,878 \\
\hline
\end{tabular}

* Valor de "d" foi fixado no limite superior. **Modelo estimado por "-2ln L mínimo". Parâmetros entre colchetes foram fixados no valor indicado. $d=$ grau de dominância; $t=$ deslocamento; $q=$ frequência alélica; $\mathrm{H}=$ herdabilidade multifatorial; $\tau \mathrm{s}=$ parâmetros de probabilidades de transmissão;

$-2 \ln \mathrm{L}=$ menos duas vezes o logaritmo neperiano do likehood $\left(\chi^{2}\right) \cdot \chi^{2}=$ qui-quadrado entre os modelos; PE = parâmetros estimados. 


\section{DISCUSSÃO E CONCLUSÃO}

A resposta ao extrato antigênico da Leishmania tende a aumentar de acordo com a idade, esses resultados foram confirmados pelos cálculos de regressão múltipla escalonada, que indicaram também uma correlação entre o fenótipo e o sexo dos indivíduos da amostra.

Nesse trabalho não foi encontrada associação significante entre o fenótipo estudado e marcadores genéticos clássicos, resultados que corroboram com os testes de associação entre sistemas ABO e Rh e leishmanioses cutâneas desenvolvidos por Esterre e Dedet (1989), e Sessa et al. (1985).

Os cálculos de correlação entre os pares dentro das famílias indicaram a existência de agregação familial com forte componente genético, isso é indicado pelo fato de ser encontrada correlação estatística significante entre "Pais e filhos" e "Mães e filhos" e de não ser encontrada correlação significante entre mães e pais em nenhuma das três variáveis utilizadas no presente trabalho.

Os presentes resultados foram compatíveis com dados da literatura, que indicam a evidência de um mecanismo genético associado à infecção por leishmaniose tegumentar (SHAW et al., 1995). Estudos de análises de segregação de mecanismos de resistência ou suscetibilidade à leishmaniose tegumentar feitos em populações do Peru e Bolívia também indicaram a presença de um gene recessivo atuando na infecção (ALCAIS, 1997).

Foram feitas análises de segregação com as três variáveis padronizadas, "MN_padrão", "MN_3_padrão" e "Qualit_padrão", devido aos três resultados apontarem para a mesma conclusão quanto ao melhor modelo de transmissão do fenótipo estudado, discute-se aqui apenas a análise da tabela 11, sendo que as análises de segregação das variáveis "MN_3_padrão" e "Qualit_padrão" se encontram em anexo.

$\mathrm{Na}$ análise de segregação complexa foi feita a comparação entre os modelos aleatório e misto, a fim de ser testada a hipótese nula de que não existe associação familial. Visto que o q.v. do modelo aleatório (modelo 2) foi 451,690 e o do modelo mendeliano misto (modelo 1) foi 427,798 tem-se $=451,690-427,798 \rightarrow \chi^{2}:=23,892 ; \mathrm{P}<0,001$, com 4 graus de liberdade

$\mathrm{O}$ valor do qui-quadrado encontrado indica que se deve optar pela hipótese alternativa, que pede a aceitação do modelo misto e, com isso, a confirmação da existência de agregação familial.

$\mathrm{Na}$ segunda comparação, feita entre o modelo misto (modelo 1) e o modelo que propõe a inexistência de um gene principal (modelo 3), a hipótese nula é a de que não há gene principal. O q.v. do modelo sem gene principal é igual a 450,963 e o do modelo misto igual a 
427,798, tem-se $=450,963-427,798=23,165 ; \mathrm{P}<0,001$, possuindo esse qui-quadrado 3 graus de liberdade. Esse valor de qui-quadrado também fala a favor da rejeição da hipótese nula e pela aceitação da hipótese alternativa, que prega a existência de um gene principal.

Na terceira comparação, feita entre o modelo misto (modelo 1) e o modelo que prega a inexistência de um componente multifatorial (modelo 4), a hipótese nula é a de que não existe componente multifatorial. O q.v. do modelo sem componente multifatorial é 427,853 enquanto que no modelo misto tem-se 427,798 . Assim, o qui-quadrado é 0,055 , pois 427,853 - 427,798, com 1 grau de liberdade, portanto, uma vez a hipótese nula aceita, pode-se rejeitar a importância da participação de um componente multifatorial na manifestação do caráter em estudo.

Comparando tanto o modelo recessivo (modelo 5) quanto o modelo recessivo (modelo 5') com o modelo misto (modelo 1), concluiu-se que os modelos de transmissão recessiva não puderam ser rejeitados, sendo que os respectivos valores de AIC indicam que o modelo mais adequado é o recessivo com $d=0$ e $\mathrm{H}=0$ (modelo 5') por ter o menor valor de AIC = 431,848 .

Os modelos aditivo (6) e dominante (7) foram comparados com o modelo misto da mesma maneira que os anteriores e, foram rejeitados, $(\mathrm{P}=<0,001$ e $\mathrm{P}=<0,001)$ AIC $=$ 463,847 e AIC = 456,857, para os modelos 6 e 7 respectivamente, apoiando assim, a hipótese da existência de um mecanismo genético recessivo.

Assim, o modelo recessivo ( $\left.5^{\prime}\right)$ passou a ser utilizado para comparação com o modelo $\tau$ s livres $(\mathrm{d}=1)$ (modelo 8), uma vez que o recessivo (5') apresentou menor valor de AIC.

Logo, são aceitas as hipóteses da existência de um mecanismo genético recessivo atuando no fenótipo, isto é, a existência de uma resposta do organismo ao extrato antigênico da Leishmania depende de um gene recessivo.

Muitos estudos populacionais em humanos mostram que grande parte das respostas dos indivíduos às doenças infecciosas se desenvolve predominantemente em indivíduos com predisposição genética e que está predisposição é causada por múltiplos genes (LIPOLDOVÁ e DEMANT, 2006).

As análises dos aspectos genéticos e imunológicos permitem comparar o efeito de genes na resposta imune dos indivíduos, o que propicia o entendimento de mecanismos específicos que fundamentem a patogênese da infecção, (LIPOLDOVÁ e DEMANT, 2006). Daí a importância de se analisar o fenótipo, que no caso é a resposta ao extrato antigênico da Leishmania em termos genéticos. 
Por meio deste trabalho foi possível aceitar a hipótese de existência de um mecanismo genético atuando na variação do fenótipo, esse mecanismo pode estar associado com o complexo principal de histocompatibilidade (MHC), pois muitos estudos indicam associação positiva entre leishmaniose cutânea e antígenos do MHC (HILL, 1998).

O MHC é constituído por glicoproteínas da membrana celular, responsável por desencadear a resposta imune, é determinado por genes que se localizam no braço curto do cromossomo 6, seus antígenos podem ser divididos nas classes I e II (SEGAL e HILL, 2003 apud KAWAMATA, 2006)

Com relação aos antígenos classe I, foi encontrada associação com HLA-Bw22 em estudo realizado na Venezuela (LARA et al., 1991) e uma baixa frequiência do antígeno HLACw7 em uma população de pacientes da Guiana Francesa (BARBIER et al., 1987), bem como a associação dos antígenos HLA-A11, -B5 e -B7 com leishmaniose cutânea difusa em egípcios (EL-MOGY et al., 1993) .

Já no caso dos antígenos de classe II, foi encontrada uma série de associações de antígenos com suscetibilidade (HLA-DQ3 e HLA-DRB1*0407, -DQA1*3011, -DPA1*401, DPB1*0101) e resistência (HLA-DRB1*1500, -DRB1*1600, -DPB1*0401) à leishmaniose cutânea (OLIVO-DIAZ et al., 2004). No caso da leishmaniose cutâneo-mucosa o antígeno HLA-DQw3 está associado com suscetibilidade, enquanto o antígeno HLA-DR2 está associado com resistência (ALVES et al., 2006).

Alguns polimorfismos em genes de citocinas como interleucina 6 (IL-6) também apresentam associações com leishmaniose (CABRERA et al., 1995). Em estudo realizado no Estado da Bahia por Castelucci et al. (2006), verificou-se que o SNP -174C no promotor do gene da IL 6 pode estar relacionado com o desenvolvimento de leishmaniose cutâneo-mucosa em pacientes com leishmaniose tegumentar.

O gene NRAMP1 ou SCL11A1, um transportador de íon divalente localizado na membrana fagossomal dos macrófagos foi identificado como um lócus de suscetibilidade em estudos feitos em camundongos para espécies de Leishmania (HILL, 2006 apud Blackwell, 1994).

Tendo em vista os resultados aqui apresentados e os vários relatos da literatura indicando a presença de mecanismos oligogênicos na resposta à infecção por Leishmania cumpre-nos apontar para a necessidade de estudos mais pormenorizados a fim de procurar a localização desses mecanismos em populações brasileiras. 


\section{REFERÊNCIAS ${ }^{*}$}

ABDI, H. The Bonferonni and Sidák Corrections for Multiple Comparisons. Encyclopedia of Measurement and Statistics. Disponível em: <http:// www.utdallas.edu/ herve/AbdiBonferro ni2007-pretty.pdf.>. Acesso em: 02 mai. 2009.

AFONSO, L. C. C.; SCOTT, P. Immune Responses Associated with Susceptibility of C57BL/10 Mice to Leishmania amazonensis. Infect. Immun., v. 61, p. 2952-2959, 1993.

AKAIKE, H. A new look at statistical model identification. IEEE Trans. Automat. Contr., v. 19, p. 716-723, 1974.

ALCAIS, A.; ABEL, L.; DAVID, C.; TORREZ, M. E.; FlANDRE, P.; DEDET, J. P. Evidence for a major gene controlling susceptibility to tegumentary leishmaniasis in a recently exposed Bolivian population. Am. J. Hum. Genet., v. 61, p. 968-979, 1997.

ALVES, C.; VIEIRA, N.; MEYER, I.; ALVES, C. O.; TORALLES, M. B. P.; OLIVEIRA, M. F. S. P. Antígenos de hiscompatibilidade humanos e dermatologia: da pesquisa para a prática clínica. An. Bras. Dermatol., v. 81, p. 65-73, 2006.

BARBIER, D.; DEMENAIS, F.; LEFAIT, J. F.; DAVID, B.; BLANC, M.; HORS, J.; FEINGOLD, N. Susceptibility to human cutaneous leishmaniasis and HLA, Gm, Km markers. Tissue Antigens, v. 30, p. 63-67, 1987.

BEIGUELMAN, B. Dinâmica dos genes nas famílias e nas populações. $2^{\mathrm{a}}$ ed. Ribeirão Preto: Sociedade Brasileira de Genética, 1994.

BEIGUElman, B. Genética de Populações Humanas. 2005. Disponível em: <http://lineu.icb.usp.br?bbeiguel/Genetica/Populacoes/. Acesso em: 15 dez. 2008.

BITTAR, R. C.; NOGUEIRA, R. S.; GONÇALVES, R. V.; RIBEIRO, V. P.; MATTOS, M. S.; OLIVEIRA-NETO, M. P.; COUTINHO, S. G.; CRUZ, A. M. T-cell responses associated with resistance to Leishmania infection in individuals from endemic areas for Leishmania (Viannia) braziliensis. Mem. Inst. Oswaldo Cruz, v. 102, p. 625-630, 2007.

BLACKWELL, J. M.; FAKIOLA, M.; IBRAHIM, M. E.; JAMIESON, S. E.; JERONIMO, S. B.; MILLER, E. N.; MISHRA, A.; MOHAMED, H. S.; PEACOCK, C. S.; RAJU, M.; SUNDAR, S.; WILSON, M. E. Genetics and visceral leishmaniasis: of mice and man. Parasite Immunol., v. 31, p. 254-266, 2009.

BLACKWELL, J. M. Genetic control of discrete phases of complex infections: Leishmania donovani as a model. J. Leukoc. Biol., v. 3, p. 31-49, 1985.

\footnotetext{
* De acordo com:

ASSOCIAÇÃO BRASILEIRA DE NORMAS TÉCNICAS. NBR 6023: Informação e documentação: referências: elaboração. Rio de Janeiro, 2002.
} 
CABELLO, P. H.; KRIEGER, H. Genioc: sistema para análise de dados de genética. Rio de Janeiro: FIOCRUZ, 1997.

CABRERA, M.; SHAW, M. A.; SHARPLES, C.; WILLIAMS, H.; CASTES, M.; CONVIT, J.; BLACKWELL, J. M. Polymorphism in tumor necrosis factor genes associated with mucocutaneous leishmaniasis. J. Exp. Med., v. 182, p. 1259-1264, 1995.

CAMARGO, L. M. A.; MOURA, M. M.; ENGRACIA, V.; PAGOTO, R. C.; BASANO, S. A.; PEREIRA, S. L. H.; CAMARGO, E. P.; BEIGUELMAN, B.; KRIEGER, H. A rural community in a Brazilian western Amazonia region: some demografhic and epidemiological patterns. Mem. Inst. Oswaldo Cruz, v. 97, p. 193-195, 2002.

CARTER, R.; MENDIS, K. N. Evolutionary and Historical Aspects of the Burden of Malaria. Clin. Microbiol. Rev., v. 15, p. 564-594, 2002.

CASTELLUCCI, L.; MENEZES, E.; OLIVEIRA, J.; MAGALHAES, A.; GUIMARAES, L. H.; LESSA, M.; RIBEIRO, S.; REALE, J.; NORONHA, E. F.; WILSON, M. E.; DUGGAL, P.; BEATY, T. H.; JERONIMO, S.; JAMIESON, S. E.; BALES, A.; BLACKWELL, J. M.; DE JESUS, A. R, CARVALHO, E. M. IL6 -174 G/C promoter polymorphism influences susceptibility to mucosal but not localized cutaneous leishmaniasis in Brazil. J. Infect. Dis., v. 194, p. 519-27. Epub 2006.

CÁSTES, M.; AGNELLI, A.; VERDE, O.; RONDON, A. J. Characterization of the cellular immune response in American cutaneous leishmaniasis. Clin. Immunol. Imunopathol., v. 27, p. 176-186, 1983.

COSTA, J. M. L. Estudo da leishmaniose cutânea difusa no Estado do Maranhão Brasil. Rev. Soc. Bras. Med. Trop. v. 31, p. 401-403, 1998.

CUBA-CUBA C. A.; MARSDEN, P. D.; BARRETTO, A. C.; JONES, T. C.; RICHARDS, F. The use of different concentrations of leishmanial antigen in skin testing to evaluate delayedhypersensitivity in American cutaneous leishmaniasis. Rev. Soc. Bras. Med. Trop., v. 18, p. $231-236,1985$.

DESJEUX, P. Human leishmaniasis: epidemiology and public health aspects. World Health Stat. Q., v. 45, p. 267-275, 1992.

EL-MOGY, M. H.; ABDEL-HAMID, I. A.; ABDEL-RAZIC, M. M.; RIZK, R. A.; ROMIA, S, A. Histocompatibility antigens in Egyptians with cutaneous leishmaniasis: a preliminary study. J. Dermatol. Sci., v.5, p. 89-91, 1993.

ESTERRE, P.; DEDET, J. P. The relationship of blood-group type to American cutaneous leishmaniasis. Ann. Trop. Med. Parasitol., v. 83, p. 345-348, 1989.

FEITOSA; M. F.; KRIEGER, H. O futuro da epidemiologia genética de características complexas. Ciênc. Saúde Coletiva, v. 7, p. 73 - 83, 2002.

FUNDAÇÃO OSVALDO CRUZ. Instituto de Tecnologia em Imunobiológicos Biomanguinhos. Antígeno para o diagnóstico da leishmaniose tegumentar por reação 
intradérmica de Montenegro. <Disponível em: <http://www.bio.fiocruz.br/ interna/ pdf/BMDCO_009_01bk\%20montenegro\%20A 4.pdf.>. Acesso em: 09 abr. 2008.

JOSE, F. F.; DA SILVA, I. M.; ARAUJO, M. I.; ALMEIDA, R. P.; BACELLAR, O.; CARVALHO, E. M. Avaliação do poder sensibilizante da reação de Montenegro. Rev. Soc. Bras. Med. Trop., v. 34, p. 537- 42, 2001.

GONTIJO, B.; CARVALHO, M. L. R. Leishmaniose tegumentar americana. Rev. Soc. Bras. Med. Trop., v. 36, p. 71-80, 2003.

GUEDES, A. C. M.; CUCÉ, L. C.; FURTADO, T. Avaliação imunológica e histopatológica da reação de Montenegro. An. Bras. Dermatol., v. 65, p.345-405, 1990.

HERWALDT, B. L. Leishmaniasis. Lancet, v. 354, p. 1191 - 1199, 1999.

HILL, A. V. S. Aspects of genetic suscetibility to human infectious diseases. Annu. Rev. Genetic., v. 40, p. 469-486, 2006.

HILL, A, V, S. The immunogenetics of human infectious diseases. Annu. Rev. Immunol., v. 16, p. 593-617, 1998.

JI, J.; SUN, J, QI, H.; SOONG. L. Analysis of T helper cell responses during infection with Leishmania amazonensis. Am. J. Trop. Med. Hyg., v. 66, p. 338 - 345, 2002.

JOSE, F. F.; DA SILVA, I. M.; ARAUJO, M. I.; ALMEIDA, R. P.; BACELLAR, O.; CARVALHO, E. M. Avaliação do poder sensibilizante da reação de Montenegro. Rev. Soc. Bras. Med. Trop., v. 34, p. 537- 542, 2001.

KAWAMATA, C. E. M. Epidemiologia genética da infecção por Trypanosoma cruzi. Tese (Mestrado) - Instituto de Biociências, Universidade de São Paulo, São Paulo, 2006.

KRIEGER, H.; FEITOSA, M. F. Genetic epidemiology of infectious disease. J. Braz. Ass. Adv. Sci., v. 51, p.191-198, 1999.

KRIEGER, H.; MORTON, N. E.; MI, M. P.; AZEVEDO, E.; FREIRE-MAIA, A.; YASUDA, N. Racial admixture in north-eastern Brazil. Ann. Hum. Genet. v. 29, p. 113-125, 1965.

LALOUEL, J. M.; MORTON, N. E. Complex segregation analysis with pointers. Hum. Hered., v. 31, p. 312 - 321, 1981.

LALOUEL, J. M.; RAO, D. C.; MORTON, N. E.; ELSTON, R. C. A unified model for complex segregation analysis. Am. J. Hum. Genet., v. 35, p. 816-826, 1983.

LAINSON, R.; SHAW, J. J. A brief history of genus Leishmania (Protozoa: Kinetoplastida) in the Americas with particular reference to Amazonian Brazil. Cienc. Cult., v. 44, p. 94-106, 1992.

LAINSON, R.; SHAW, J. J. New World Leishmaniasis: The Neotropical Leishmania Species. In: TOPLEY, W. W. C.; WILSON, S. G. S.; KREIER, J. P.; WAKELIN, D.; COX, F. E.G. Microbiology and Microbial Infections. 9. ed. London: Hodder Arnold, 1998. v. 5, p. 242266. 
LARA, M. L.; LAYRISSE, Z.; SCORZA, J. V.; GARCIA, E.; STOIKOW, Z.; GRANADOS, J.; BIAS, W. Immunogenetics of human American cutaneous leishmaniasis. Study of HLA haplotypesin 24 families from Venezuela. Hum. Immunol., v. 30, p. 129-135, 1991.

LAURENTI, M. D.; DOS SANTOS, S. V. M.; SECUNDINO, N. F.; CORBETT, C. E.; PIMENTA, P. P. Saliva of laboratory-reared Lutzomyia longipalpis exacerbates Leishmania (Leishmania) amazonensis infection more potently than saliva of wild-caught Lutzomyia longipalpis. Parasitol. Int., 2009. Epub ahead of print.

LIPOLDOVÁ, M; DEMANT, P. Genetic susceptibility to infectious disease: lessons from mouse models of leishmaniasis. Nature, v. 7, p. 294 -305, 2006.

LYNCH, M.; WALSH, B. Genetics and analysis of quantitative traits. Canada: Sinauer Associates, 1998.

MACHADO, P. R. L.; ARAÚJO, M. I. A. S.; CARVAlHO, L.; CARVALHO, E. M. Immune response mechanisms to infections. An. Bras. Dermatol., v. 79, p. 647-664, 2004.

MASSARO, D. B.; REZENDE, D. S.; CAMARGO, L. M. A. Study of the triatomine fauna and occurrence of Chagas disease in Monte Negro, Rondonia, Brazil. Rev. Bras. Epidemiol., v. 11, p. 228-240, 2008.

MEDDEB-GARNAOUI, A.; ZRELLI, H.; DELLAGI, K. Effects of tropism and virulence of Leishmania parasites on cytokine production by infected human monocytes. Clin. Exp. Immunol., v. 155, p. 199-206, 2008.

MINISTÉRIO DA SAÚDE. Rede Internacional De Informações Para a Saúde. Indicadores de morbidade e fatores de risco. Disponível em: <http://tabnet.datasus.gov.br /cgi/tabcgi.exe?idb2005/d0204.def >. Acesso em: 14 fev. 2007.

MINISTÉRIO DA SAÚDE. Secretaria de Vigilância em Saúde. Departamento de Vigilância Epidemiológica. Atlas de Leishmaniose tegumentar Americana. Editora MS, Brasília, 2006.

MINISTÉRIO DA SAÚDE. Secretaria de Vigilância em Saúde. Departamento de Vigilância Epidemiológica. Manual de Vigilância da Leishmaniose Tegumentar Americana. Brasília: MS, 2007.

MONTENEGRO J. Cutaneous reaction in leishmaniasis. Arch. Derm. Syphilol., v. 13, p. 187-184, 1926.

MORTON, N. Outline of genetic epidemiology. New York: Karger, 1982.

NOGUEIRA, M. F.; SOTTO, M.; CUCÉ, L.C. American tegumentary leishmaniasis: langerhans cells in Montenegro skin test. Rev. Inst. Med. Trop., v. 50, p. 283-286, 2008.

OLIVO-DIAZ, A.; DEBAZ, H.; ALAEZ, C.; ISLAS, V. J.; PEREZ-PEREZ, H.; HOBARTM, O.; GORODEZKY, C. Role of HLA class II alleles in susceptibility to and protection from localized cutaneous leishmaniasis. Hum. Immunol., v. 65, p. 255-261, 2004. 
ORGANIZAÇÃO MUNDIAL DA SAÚDE. Leishmaniasis Parasitic Diseases. Disponível em: <http://www.who.int/lvacine_research/diseases/soa_parasitic/ en/index3.html>. Acesso em: 19 dez. 2007.

ORGANIZAÇÃO MUNDIAL DA SAÚDE. Leishmaniasis the disease and its epidemiology. Disponível em: < http://www.who.int/leishmaniasis/disease_ epidemiology/en/index.html>. Acesso em: $11 \mathrm{dez} 2006$.

ORGANIZAÇÃO MUNDIAL DA SAÚDE. Weekly epidemiological record. World Health Organ., v. 77, p. 365-372, 2002.

PASSOS, J. P. S. Padronização do método de produção do antígeno para Intradermorreação de Montenegro. Tese (Mestrado) - Instituto Nacional de Controle de Qualidade em Saúde Fundação Oswaldo Cruz, Rio de Janeiro, 2004.

REIS, L. C.; BRITO, M. E. F.; SOUZA, M. A.; PEREIRA, V. R. A. Mecanismos imunológicos envolvidos na resposta celular e humoral na leishmaniose tegumentar americana. Rev. Pat. Trop., v. 35, p. 103-116, 2006.

REY, L. Parasitologia. 3 ed. Rio de Janeiro: Guanabara Koogan, 2001.

RODAS, L. A. C.; POLETTO, D. W. Leishmaniose Visceral Americana. Superintendência de Controle de Endemias do Estado de São Paulo, 2000. Disponível em: $<$ http://www.sucen.sp.gov.br/doencas/leish_visc/texto_leishmaniose_visceral_americana.htm >. Acesso em: $11 \mathrm{dez} 2006$.

SESSA, P. A.; PEREIRA, F. E. L.; BARROS, G. C.; MATTOS, E. A.; DAHER, V. R. Blood groups of the $\mathrm{ABO}$ and $\mathrm{Rh}$ systems and muco-cutaneous leishmaniasis . Braz. J. Genet., v. 8, p. 183-185, 1985.

SHAW, J. J; LAINSON, R. Leishmaniasis in Brazil XI: observations on the morphology of Leishmania of the brazilensis and mexicana complexes. J. Trop. Med. Hyg., v. 79, p. 9-13, 1976.

SHAW, M. A.; DAVIES, C. R.; LLANOS-CUENTAS, E. A.; COLLINS, A. Human genetic susceptibility and infection with leishmania peruviana Am. J. Hum. Genet., v. 57, p. 11591168, 1995.

SILVA, L. J.; CAMARGO, V. L. F. N. Infectologia: As Leishmanioses. Hosp. Pract., São Paulo, v. 36, 2004.

SILVEIRA, F. T.; ISHIKAWA, E. A.; DE SOUZA, A. A.; LAINSON, R. An outbreak of cutaneous leishmaniasis among soldiers in Belém, Pará State, Brazil, caused by Leishmania (Viannia) lindenbergi n. sp. A new leishmanial parasite of man in the Amazon region. Parasite, v. 9, p. 43-50, 2002.

SILVEIRA, F. T.; LAINSON, R.; CORBETT, C. E. P. Clinical and Immunopathological Spectrum of American Cutaneous Leishmaniasis with Special Reference to the Disease in Amazonian Brazil. Mem. Inst. Oswaldo Cruz, v. 99, p. 239-251, 2004. 
SILVEIRA, F. T.; LAINSON, R.; SHAW, I. L.; DE SOUZA, A. A.; ISHIKAEA, P. A.; BRAOA, R. R. Cutaneous Leishmaniasis due to Leismmania (Leishmania) amazonensis in Amazonian Brazil, and the significance of a negative Montenegro skin-test in human infections. Trans. R. Soc. Trop. Med. Hyg., v. 35, p. 735 - 738, 1991.

STÄGER, S.; SMITH, D. F.; KAYE, P. M. Immunization with a recombinant stage-regulated surface protein from Leishmania donovani induces protection against visceral leishmaniasis. J. Immunol., v. 165, p. 7064-7071, 2000. 


\section{ANEXOS}

Tabela A.1 - Análise de segregação em "MN_3_padrão”, levando em conta 102 famílias nucleares com 310 indivíduos.

\begin{tabular}{|c|c|c|c|c|c|c|c|c|c|c|c|c|c|}
\hline Modelo & $d$ & $t$ & $q$ & $\boldsymbol{H}$ & $\tau_{1}$ & $\tau_{2}$ & $\tau_{3}$ & $-2 \ln L$ & $\chi^{2}$ & $\boldsymbol{P}$ & Teste & $P E$ & $A I C$ \\
\hline 1. Misto & $-0,059$ & 1,759 & 0,548 & 0,025 & {$[1]$} & {$[0,5]$} & {$[0]$} & 432,709 & & & & 4 & 440,709 \\
\hline 2. Aleatório & {$[0]$} & {$[0]$} & {$[0]$} & {$[0]$} & - & - & - & 448,633 & 15,925 & 0,006 & 2 vs. 1 & 0 & 448,633 \\
\hline 3. Sem gene principal & {$[0]$} & {$[0]$} & {$[0]$} & 0,162 & {$[1]$} & {$[0,5]$} & {$[0]$} & 446,887 & 14,178 & 0,002 & 3 vs. 1 & 1 & 448,887 \\
\hline 4. Sem componente multifatorial & $-0,043$ & 1,767 & 0,548 & {$[0]$} & {$[1]$} & {$[0,5]$} & {$[0]$} & 433,024 & 0,315 & 0,540 & 4 vs. 1 & 3 & 439,024 \\
\hline 5. Recessivo $(d=0)$ & {$[0]$} & 1,828 & 0,549 & 0,018 & {$[1]$} & {$[0,5]$} & {$[0]$} & 432,968 & 0,260 & 0,650 & 5 vs. 1 & 3 & 438,968 \\
\hline $5^{\prime}$. Recessivo $(d=0, H=0)$ & {$[0]$} & $\mathbf{1 , 8 2 0}$ & 0,549 & {$[\mathbf{0}]$} & {$[1]$} & {$[0,5]$} & {$[0]$} & 433,141 & 0,432 & 0,790 & $5^{\prime}$ vS. 1 & 2 & 437,141 \\
\hline 6. Aditivo $(d=0,5)$ & {$[0,5]$} & 3,292 & 0,044 & 0,055 & {$[1]$} & {$[0,5]$} & {$[0]$} & 444,180 & 11,472 & $<0,001$ & 6 vs. 1 & 3 & 450,180 \\
\hline 7. Dominante $(\mathrm{d}=1)$ & {$[1]$} & 1,339 & 0,075 & 0,060 & [1] & {$[0,5]$} & {$[0]$} & 444,456 & 11,747 & $<0,001$ & 7 vs 1 & 3 & 450,456 \\
\hline 8. $\tau \mathrm{s}$ livres $(\mathrm{d}=1)$ & [1] & 6,254 & 0,921 & 0,094 & 1,000 & 0,000 & $-0,002$ & 440,914 & 7,773 & 0,009 & 8 vs $5^{\prime}$ & 6 & 452,914 \\
\hline
\end{tabular}

* Valor de "d" foi fixado no limite superior. **Modelo estimado por "-2ln L mínimo". Parâmetros entre colchetes foram fixados no valor indicado. $d=$ grau de dominância; $t=$ deslocamento; $q=$ frequência alélica; H= herdabilidade multifatorial; $\tau \mathrm{s}=$ parâmetros de probabilidades de transmissão;

$-2 \ln \mathrm{L}=$ menos duas vezes o logaritmo neperiano do likehood $\left(\chi^{2}\right) \cdot \chi^{2}=$ qui-quadrado entre os modelos; PE $=$ parâmetros estimados. 
Tabela A.2 - Análise de segregação em “Qualit_padrão”, levando em conta 102 famílias nucleares com 310 indivíduos.

\begin{tabular}{|c|c|c|c|c|c|c|c|c|c|c|c|c|c|}
\hline Modelo & $d$ & $t$ & $q$ & $\boldsymbol{H}$ & $\tau_{1}$ & $\tau_{2}$ & $\tau_{3}$ & $-2 \ln L$ & $\chi^{2}$ & $P$ & Teste & $P E$ & $A I C$ \\
\hline 1. Misto & 0,049 & 3,086 & 0,314 & 0,003 & {$[1]$} & {$[0,5]$} & {$[0]$} & 266,800 & & & & 4 & \\
\hline 2. Aleatório & {$[0]$} & {$[0]$} & {$[0]$} & {$[0]$} & - & - & - & 407,374 & 140,574 & $<<0,001$ & 2 vs. 1 & 0 & 407,374 \\
\hline 3. Sem gene principal & {$[0]$} & {$[0]$} & {$[0]$} & 0,292 & {$[1]$} & {$[0,5]$} & {$[0]$} & 403,883 & 137,083 & $<<0,001$ & 3 vs. 1 & 1 & 405,883 \\
\hline 4. Sem componente multifatorial & $-0,006$ & 19,490 & 0,036 & {$[0]$} & {$[1]$} & {$[0,5]$} & {$[0]$} & 376,264 & 109,464 & $<<0,001$ & 4 vs. 1 & 3 & 382,264 \\
\hline 5. Recessivo $(d=0)$ & {$[0]$} & 20,140 & 0,035 & 0,069 & {$[1]$} & {$[0,5]$} & {$[0]$} & 373,043 & 106,243 & $<<0,001$ & 5 vs. 1 & 3 & 379,043 \\
\hline 5'. Recessivo $(d=0, H=0)$ & {$[0]$} & 3,022 & 0,313 & {$[0]$} & {$[1]$} & {$[0,5]$} & {$[0]$} & 268,538 & 1,737 & 0,400 & 5' vs. 1 & 2 & 272,538 \\
\hline 6. Aditivo $(d=0,5)$ & {$[0,5]$} & 0,037 & 0,548 & 0,287 & {$[1]$} & {$[0,5]$} & {$[0]$} & 403,904 & 137,104 & $<<0,001$ & 6 vs. 1 & 3 & 409,904 \\
\hline 7. Dominante $(d=1)$ & {$[1]$} & 0,015 & 0,304 & 0,287 & {$[1]$} & {$[0,5]$} & {$[0]$} & 403,903 & 137,103 & $<<0,002$ & 7 vs 1 & 3 & 409,903 \\
\hline 8. $\tau$ s livres $(\mathrm{d}=1)$ & {$[1]$} & 8,370 & 0,918 & 0,079 & 1,000 & 0,000 & 0,000 & 376,368 & 107,830 & $<<0,001$ & 8 vs $5^{\prime}$ & 6 & 388,368 \\
\hline
\end{tabular}

* Valor de "d" foi fixado no limite superior. **Modelo estimado por “-2ln L mínimo”. Parâmetros entre colchetes foram fixados no valor indicado. $d=$ grau de dominância; $t$ = deslocamento; $q$ = frequência alélica; $\mathrm{H}=$ herdabilidade multifatorial; $\tau \mathrm{s}=$ parâmetros de probabilidades de transmissão;

$-2 \ln \mathrm{L}=$ menos duas vezes o logaritmo neperiano do likehood $\left(\chi^{2}\right) \cdot \chi^{2}=$ qui-quadrado entre os modelos; PE = parâmetros estimados. 